Check for updates

Cite this: Mater. Adv., 2021

2. 1485

Received 23rd December 2020

Accepted 20th January 2021

DOI: 10.1039/d0ma01011a

rsc.li/materials-advances

\title{
Nanocellulose: the next super versatile material for the military
}

\author{
Mohd Nor Faiz Norrrahim, (D) ${ }^{a}$ Noor Azilah Mohd Kasim, (D) *ab \\ Victor Feizal Knight, (D) ${ }^{a}$ Farhana Aziz Ujang, ${ }^{a}$ Nurjahirah Janudin, ${ }^{a}$ \\ Mas Amira Idayu Abdul Razak, ${ }^{\text {ac }}$ Noor Aisyah Ahmad Shah, \\ Siti Aminah Mohd Noor, ${ }^{\text {ab }}$ Siti Hasnawati Jamal, ${ }^{b}$ Keat Khim Ong ${ }^{\text {ab }}$ and \\ Wan Md Zin Wan Yunus ${ }^{\text {abd }}$
}

\begin{abstract}
Military systems have become more complex, and the development of future advanced materials for defence applications has received much attention. Nanocellulose has been identified as a 'super versatile material' that will become a replacement material for many applications including in the military. Nanocellulose can be synthesized from discarded fibers that are left over from forestry and agricultural waste that can be transformed into high-value products. Thanks to its interesting properties, comprising low thermal expansion coefficient, high aspect ratio, high crystallinity, and good mechanical and optical properties, nanocellulose has emerged as a new material class for high end military products such as bulletproof vests, fire-retardant materials, as a component of propellants and filtration materials, and in textile, electronic and energy products. Therefore, in this review, current and future applications of nanocellulose in the military are critically discussed. This review is intended to impart to readers some of the excitement that currently surrounds nanocellulose research, and it's fascinating chemical and physical properties and applications in the military.
\end{abstract}

${ }^{a}$ Research Centre for Chemical Defence, Universiti Pertahanan Nasional Malaysia, Kem Perdana Sungai Besi, 57000 Kuala Lumpur, Malaysia

${ }^{b}$ Department of Chemistry and Biology, Centre for Defence Foundation Studies, Universiti Pertahanan Nasional Malaysia, Kem Perdana Sungai Besi 57000 Kuala Lumpur, Malaysia. E-mail: azilah@upnm.edu.my ${ }^{c}$ Department of Defence Science, Faculty of Defence Science and Technology, Universiti Pertahanan Nasional Malaysia, Kem Perdana Sungai Besi 57000 Kuala Lumpur, Malaysia

${ }^{d}$ Research Centre for Tropicalisation, Universiti Pertahanan Nasional Malaysia, Kem Perdana Sungai Besi, 57000 Kuala Lumpur, Malaysia

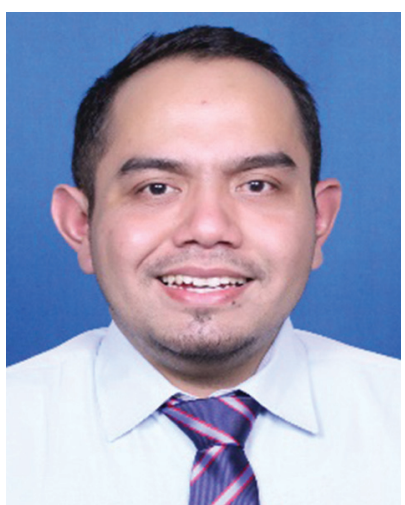

Mohd Nor Faiz Norrrahim
Mohd Nor Faiz Norrahim completed his PhD at the Universiti Putra Malaysia in 2018. He is now working as a post-doctoral fellow in Research Center for Chemical Defence, National Defence University of Malaysia. He has secured several awards for innovations and technology developments. His research interests include nanotechnology, bio-adsorbents, bio-polymers, bio-composites and biotechnology.

\section{Introduction}

Global military expenditure has seen its largest annual increase in a decade. According to new data from the Stockholm International Peace Research Institute (SIPRI), total global military expenditure increased to US\$ 1917 billion in the year 2019 which was an increase of $3.6 \%$ from the year $2018 .^{1}$ This amount also includes a large spend on military research and development (R\&D). In 2017, countries such as the United

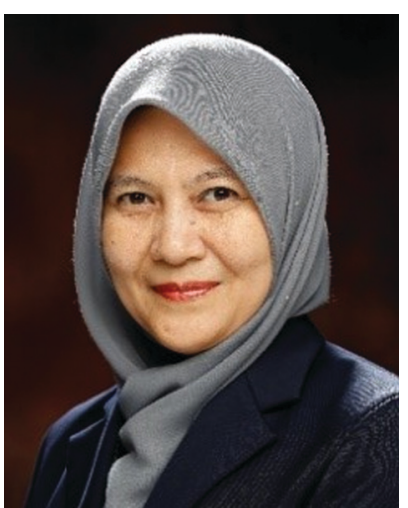

Noor Azilah Mohd Kasim
Noor Azilah Mohd Kasim is working as an Associate Professor at the Department of Chemistry and Biology, Center for Defence Foundation Studies, National Defence University of Malaysia. She has secured several innovation awards and also research grants. Her research interests are organic chemistry, chemistry, materials science and sensor development. 
States of America, South Korea, Germany, Turkey and Japan have spent billions of dollars on military R\&D. ${ }^{2}$ R\&D creates the foundation for new and improved technologies that underpin a wide range of applications especially addressing the changing face of conflict over the last two decades. These applications include advanced materials for various purposes such those used in the development of pharmaceuticals and medical treatment, combating corrosion and microbial contamination, advanced aircraft, weapons, preserved food supplies for field operations and recent work on portable energy sources and electronics used in military equipment.

Nanotechnology has become an agenda of 'hype' among scientists due to its huge contribution in our current modern life. Applications of engineered nanomaterials have heralded a new generation for the military. According to a report by the National Research Council, advanced materials in the military must satisfy diverse requirements which encompass speed, strength, precision, survivability, signature, material selection, cost, weight, and commonality. ${ }^{3}$ For example, through the use of these nanomaterials, ships may be able to travel at speeds of more than 75 knots; very lightweight tanks will travel at speeds of up to 75 miles per hour; and weapons will be delivered at hypersonic speeds.

This R\&D in materials and processes is needed to improve existing materials and to achieve breakthroughs with new materials and combinations thereof. There are 13 criteria of specific properties needed for military usage and these are as follows: ${ }^{3}$

- Lightweight materials that provide equivalent functionality.

This is an important requirement for many military systems ranging from tanks to the load bearing equipment carried by each soldier. Military forces require at the very least the same functionality as is present with today's systems, for example, the ability to withstand enemy fire as well as additional new functionalities particularly for sensing surrounding environments, communicating with and responding to other elements of the military force, increased lethality of weapons, and being able to respond effectively to new threats.

- Materials that enhance protection and survivability.

It is critical that military forces are able to withstand enemy fire. $R \& D$ must be carried out to discover new approaches to provide for this ability, particularly with a reduced weight for the same equivalent protection. Materials that perform multiple functions simultaneously are a promising area of $R \& D$ being actively explored.

- Stealth materials.

As the deployment range of military operations increases, it becomes both tactically and strategically important that certain military assets remain unseen or unobserved by adversaries which can be achieved using stealth technologies. This is an important area of research, particularly using multifunctional structural materials that incorporate a stealth capability and with electronic and/or optical properties that may either actively or passively create a state of invisibility.

- Electronic and photonic materials for high-speed communications.
Communications, control and coordination of military assets in tomorrow's armed forces will require extremely broad bandwidth and secure transmission, reception, and interpretation capabilities. To achieve this, materials that will enable these capabilities are needed, be they optical, electronic, or any combination thereof. Furthermore, military force elements will typically be under constraints with regards weight, speed of transmission, or both thus defining that the desired functionality has to be achieved in as small a volume with as little weight as possible.

- Sensor and actuator materials.

Upon a battlefield or field of conflict, various command and control networks consist of many interconnected elements with numerous demands, among which is the need to detect signals that may be of many different types. R\&D of sensor and actuator materials and their subsequent integration into larger systems are critical to the development of effective and efficient military systems. An emerging area of need is in the area of detectors or sensors against chemical and biological agents, both as weapons and those which have dual-use characteristics.

- High-energy-density materials.

There is a need for explosive materials that have a higher energy per unit mass than the current explosives. These new materials should have the capability of being tailored to maximize lethality against specific threats. Similarly, the successful R\&D of new high-energy-density propellants could make it possible to decrease the mass of the propellant while increasing the range of the projectile fired.

- Materials that improve propulsion technology.

Improved propulsion ability is very much desired whether by land, sea, air or in space. Numerous materials have been investigated to address the need for high energy density fuels for improved undersea propulsion. Besides this, materials suitable for hypersonic propulsion systems are a priority for future Air Force systems.

- Multifunctionality.

One way to reduce weight and volume is by using materials that can perform at least two functions (for example: stealth properties and structural support). Multifunctionality can be thought of as being on two scales: (1) mesoscopic (e.g., as a coating) or macroscopic (for example: load-bearing), and (2) microscopic or nano, in which case multiple physical phenomena are produced through suitable molecular design or architectural texture. The concept of multifunctionality encompasses many classes of materials and applications: Structural materials may be self-interrogating or self-healing, provide stealth properties, or protect against enemy fire; or may be microscopic materials or systems that combine sensing, motion, analysis, communications, and action.

- Self-healing and self-diagnosing.

Materials with self-healing and self-diagnosing properties address several military needs, from improving survivability to minimizing system maintenance. These properties provide obvious advantages and consequential savings.

- Low total system cost. 
Cost is a primary criterion for military acquisitions and will be for the foreseeable future. Materials that result in low total system cost (including procurement, operating, maintenance and disposal costs) will have a decided advantage, even if their initial cost is high compared to other choices.

- Low maintenance.

Since systems for defence are likely to be in use for many decades, materials that do not require extensive, active maintenance are preferred. An example is the Navy's critical need to reduce the necessity of paint chipping, a resource-intensive task that adds significantly to the Navy's manpower requirements.

- High reliability.

The consequences of material failure in military systems can be dire and impact on the availability of military assets to meet operational needs. This need for materials and manufacturing processes that are highly reliable spans all classes of materials.

- Environmental acceptability.

The military has become increasingly sensitive towards the environmental impact of military activities. The use of environmentally friendly energy sources and the efficient use of power are areas where R\&D continues to be needed. Materials and processes for military systems should have as little adverse impact on the environment as possible. Among areas of special concern are the decommissioning and disposal of obsolete systems, which would include the recycling and reuse of as much of an old system as possible and the decommissioning and disposal of obsolete facilities where they need to be made safe prior to disposal and potential repurposing of use.

Newly developed technology regarding the materials used for military needs require these properties, whether alone or in combination. Interestingly, nanocellulose could very well be the best candidate to meet the above-mentioned criteria. Nanocellulose is a material derived from cellulose that has been downsized into the nanoscale. Cellulose is a material widespread in nature and may be obtained from many natural sources such as wood, cotton, and vegetable biomass. Cellulose is the most abundant and renewable natural resource on earth. ${ }^{4}$ It is stronger than Kevlar and has a high tensile strength that is 8 times higher than stainless steel. ${ }^{5}$

Nanocellulose materials have therefore emerged as promising materials and received tremendous demand for use in various broad applications such as materials for construction, packaging, automotive components, energy systems, transportation, sensors and in various biomedical fields. ${ }^{6-15}$ Nanocellulose is usually utilised to improve the final properties of the materials used to meet specific applications. This is because of several interesting properties of nanocellulose which will be discussed in the following section.

Therefore, in this review, current and potential applications of nanocellulose for the military are discussed. In each application, the role of nanocellulose in improving the final properties of the material designed is critically discussed. To the best of our knowledge, this is the first review that focuses on the military applications of nanocellulose.

\section{Properties, classification and modification of nanocellulose}

Nanocellulose can be defined as a cellulose material having dimensions of 100 nanometer (nm) or less with an extremely high specific area, high porosity with excellent pore interconnectivity, high stiffness, electric conductivity, low weight, low toxicity and low immunogenicity, and high biodegradability. ${ }^{16-20}$ The hydroxyl groups, $-\mathrm{OH}$, on the cellulose backbone of nanocellulose enable facile functionalization of nanocellulose that introduces the desired functionality that can benefit several applications. Fig. 1(a) shows the chemical structure of cellulose where it contains an abundance of hydroxyl groups. Meanwhile, Table 1 summarizes the importance of these special characteristics of nanocellulose.

Nanocellulose can be classified into three types, which are cellulose nanofibers (CNF), cellulose nanocrystals (CNC) and bacterial nanocellulose (BNC). ${ }^{29,30} \mathrm{CNF}, \mathrm{CNC}$ and $\mathrm{BNC}$ are all in nanoscale size, but they are different in terms of their shape, size and composition. ${ }^{31}$ The morphologies of CNC, CNF and BNC produced using different methods are shown in Fig. 1(b). Both CNF and CNC are plant-based nanocelluloses and BNC is considered as a microbial-based nanocellulose. For CNF and CNC production, the fabrication methods involve the disintegration of plant cellulose using mechanical, physical and chemical methods or a combination thereof. ${ }^{13,32}$ BNC is the only nanocellulose type that can be produced biotechnologically by microorganisms resulting in high purity of hydrogels, high mechanical strength and interconnecting micropore system similar to CNF and CNC. ${ }^{33-36}$ Recently, a scientist has developed a novel Mobile Matrix Reservoir Technology (MMR Tech). ${ }^{36}$

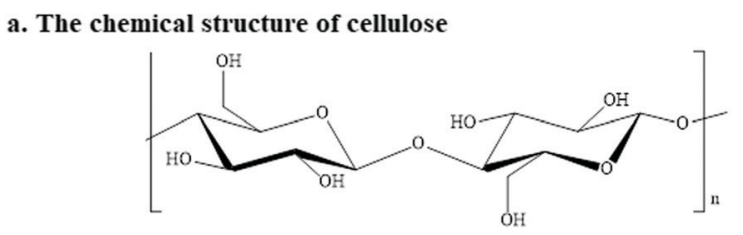

b. Morphology of cellulose nanocrystals, cellulose nanofibers and bacteria nanocellulose

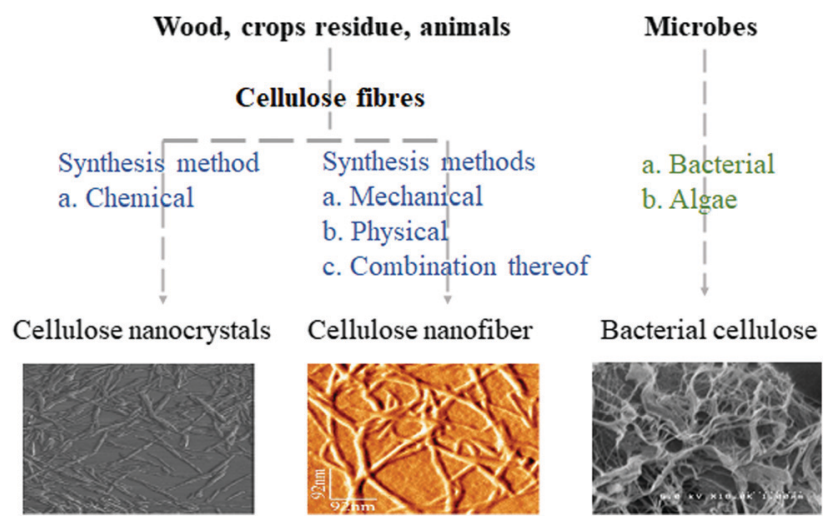

Fig. 1 (a) Chemical structure of cellulose, (b) morphology of cellulose nanocrystals, cellulose nanofibers and bacterial nanocellulose. This figure was redrawn and adapted from ref. 13 and 21. 
Table 1 Several properties of nanocellulose

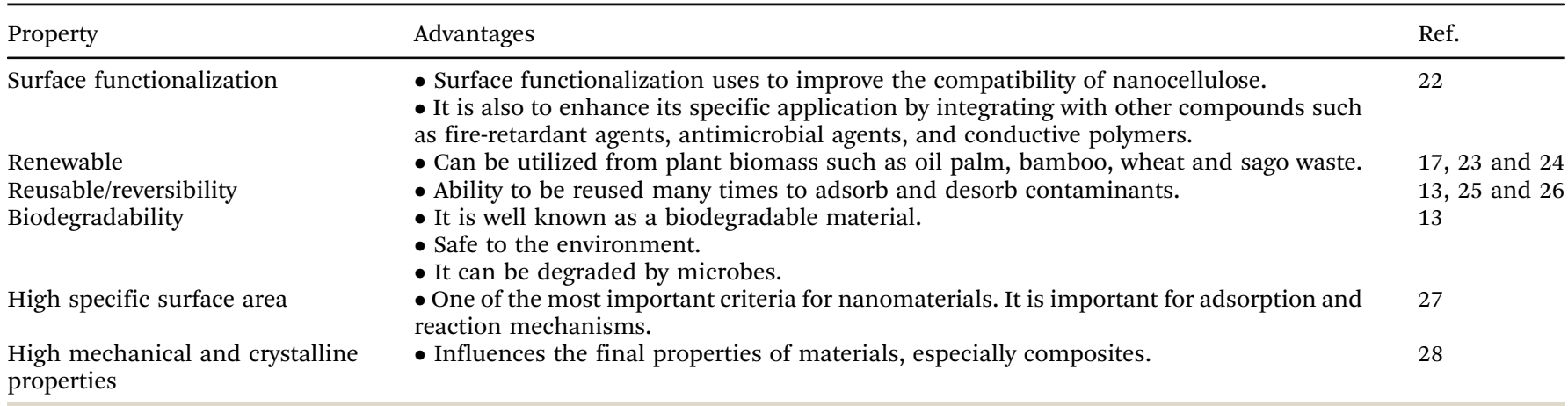

By using this developed technology, the shapes, dimensions, surface properties and nanonetwork structures can be designed in a process-controlled manner. The formed multilayer materials open up new applications in several fields such as medical and military technology. Klemm et al. (2020) ${ }^{36}$ had found that this technology is highly applicable in the development of medical materials for cardiovascular and visceral surgery and drug delivery systems.

Modification of nanocellulose is important for several applications. This process enables the alteration of its behavior and characteristics that allows it to be used under different conditions. ${ }^{37}$ This can be carried out using various different strategies of surface functionalization such as oxidation, carboxylation, etherification, esterification, silylation and polymer grafting which typically involve the chemistry of hydroxyl functions. ${ }^{22}$ Surface carboxylation is a common modification strategy to improve the chemical properties of nanocellulose. ${ }^{38}$
The surface properties and interfacial compatibility of nanocellulose are important to its application performance. This is because the stable dispersion of nanocellulose in polymer matrices is very crucial to improve the enhancement effect of nanocomposites. Charge repulsion and steric hindrance are the keys to the dispersity of nanocellulose. ${ }^{38}$ Appropriate modification as listed above can effectively increase the dispersity of nanocellulose. According to Chu et al. (2020), ${ }^{38}$ the advantages of functionalized nanocellulose in composites far outweigh their costs and concerns. Therefore, more further studies are still needed to fully understand the dispersion mechanisms of nanocellulose. ${ }^{38}$

Fig. 2 shows some common surface functionalizations carried out on nanocellulose. Besides that, as is seen in Fig. 3, a search was carried out using www.lens.org using the keyword 'functionalization of nanocellulose' and it was found that

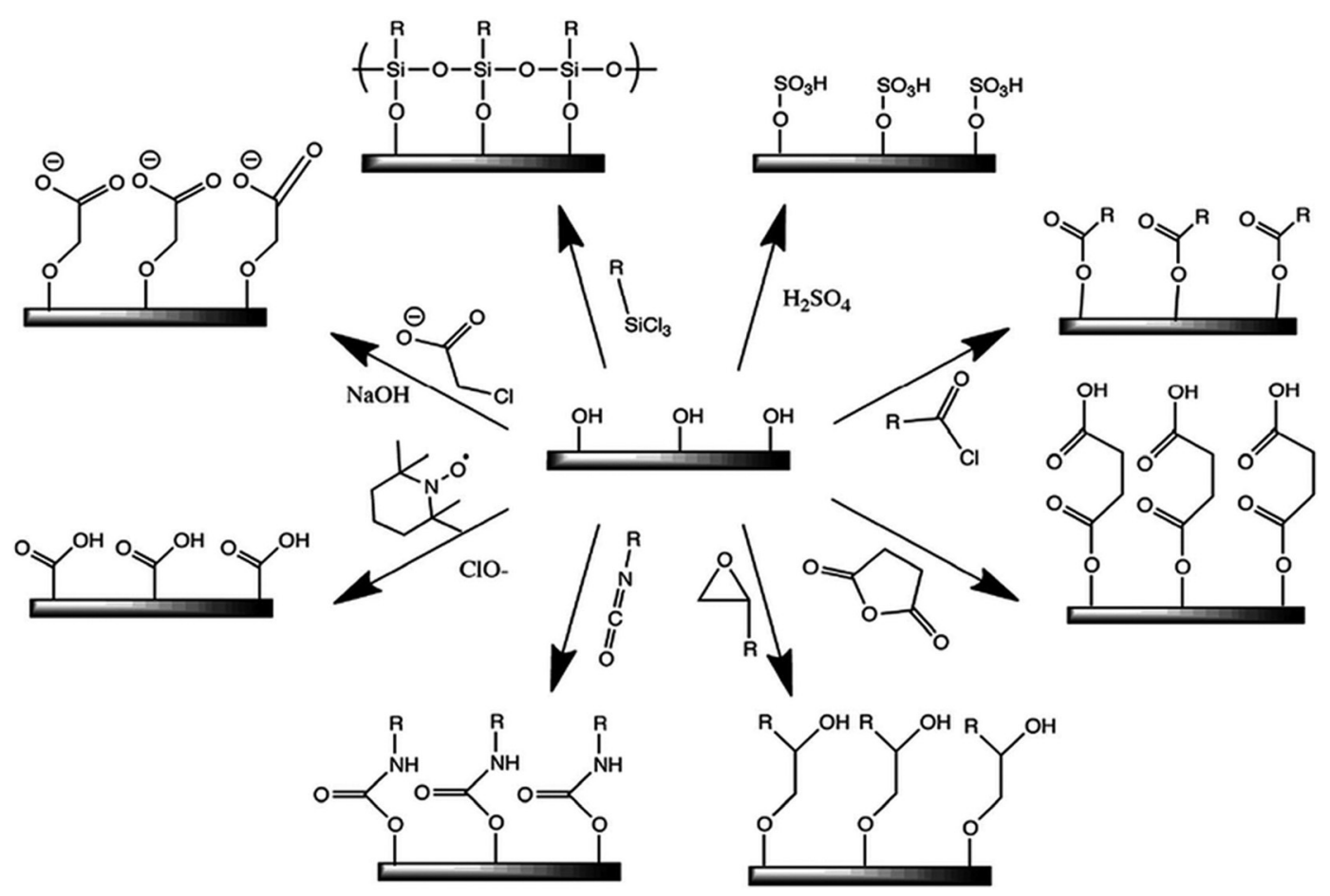

Fig. 2 Common surface functionalizations on nanocellulose. Reproduced from ref. 37 with permission from the Royal Society of Chemistry. 


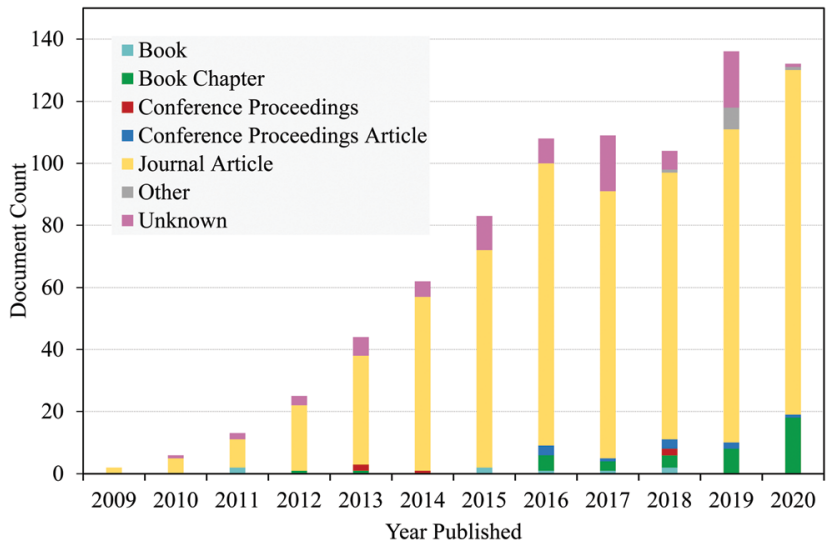

Fig. 3 A chart of published manuscripts focusing on the functionalization of nanocellulose.

manuscripts focusing on the functionalization of nanocellulose have increased in recent years. ${ }^{39}$ Thus, demonstrating that R\&D on the functionalization of nanocellulose continues to gain much interest among scientists through this decade.

\section{Application of nanocellulose for military packaging}

The aims of packaging materials in the military are somehow different from commercial packaging. Some of the military equipment needs to be preserved for a long duration of time. Military preservation refers to the materials or methods needed to protect items during shipment, handling, storage and distribution. Thus, packaging materials that have excellent mechanical strength, waterproof and excellent barrier properties are more prominent in the military as compared to commercial packaging.

Packaging materials in the military are usually used to protect food, beverages, electronics, and electrical and assembled parts. Several categories of military packaging where nanocellulose can be applied include bags, chipboard cartons, food package, cushioning, military fastpacks, tapes and wraps. However, research on the application of nanocellulose for those categories is not fully explored yet. Military scientists have long realized the need for thorough and effective packaging standards especially when the loss of transported resources through faulty packaging hampers military efforts. Specifically, it was found during the transition from World War I to World War II that shipping containers used for transporting provisions and equipment could not stand up to the rigours of overseas travel. ${ }^{40}$ The emphasis at that time was only on conserving packing materials and exterior attractiveness for marketing purposes. Moisture and other elemental impacts on the transported provisions and equipment were not taken into account. The reasons that military standards for transport packaging emerged was due to shortcomings in packaging that delayed or hindered crucial functions. Military packaging standards are meant to protect equipment, ensure combat readiness and maintain superior performance for all shipments. Therefore, R\&D on military packaging continues to discover both new materials as well as potential improvements to the materials used for it.

Nanocellulose has been widely studied as a component of materials used for a variety of packaging needs. ${ }^{41}$ Abdul Khalil et al. (2016) ${ }^{42}$ reported that nanocellulose-based packaging has been used by various large corporations. For example, the Unisource Company has produced bamboo-nanocellulosebased packaging which was specifically used to safely transport electronic devices especially laptops around the world. Moreover, nanocellulose can be used in packaging that meets military standards for materials that enhance protection and survivability, environmental acceptability and multifunctionality as has been discussed in the introduction to this article. The mechanical properties of packaging materials are one of the important aspects for the military.

Nanocellulose paper films are usually brittle in nature. It also readily tends to swell when exposed to water. Thus, it limits their applications in military packaging. Recent research also pointed out various promising strategies to prepare the nanocellulose-based paper as packaging materials with superior properties. ${ }^{43}$ Several promising approaches involved the usage of multiple layers of different materials or additives such as waxes, high-aspect ratio nano-clays and surface-active compounds in functionalization to the nanocellulose. For example, nanocellulose can be impregnated with phenolic resin to improve the final mechanical properties as packaging materials. ${ }^{43}$ By using an impregnation approach to an existing nanocellulose, high contents of nanocellulose paper can be obtained. Besides that, scientists had developed several functionalized nanocelluloses to make it superhydrophobic. ${ }^{13}$ Compounds such as titanium dioxide and stearoyl chloride can be functionalized with nanocellulose to decrease its hydrophilicity properties. ${ }^{44,45}$ Thus, this will significantly reduce the swelling capacity of nanocellulose paper upon exposure to water.

Nanocellulose is known to be able to increase the mechanical strength of other packaging materials. Several types of polyolefins have been used in packaging materials; for example, polyethylene, polypropylene, and polyethylene terephthalate have had their mechanical performance greatly increased with the addition of small amounts of nanocellulose, usually 1 to $5 \%$. Table 2 shows the mechanical properties of these composites which have been improved by the addition of nanocellulose.

Beyond that, biopolymers such as polylactic acid, starch and polyhydroxyalkanoates are known materials for use as biodegradable packaging. These biopolymers are reported to be cheaper than conventional polystyrene trays. ${ }^{53}$ They can be naturally degraded after being discarded. Through the use of these biopolymers, the burden of the army for disposing of waste will be reduced whereby these biopolymers after being thrown into landfill after use and thus naturally and safely degraded in the environment. However, these biopolymers have several weaknesses especially their low mechanical performance and thermal stability which limits their application as a packaging material. ${ }^{54}$ Thus, to improve these properties nanocellulose is 
Table 2 Mechanical properties of nanocellulose reinforced composites

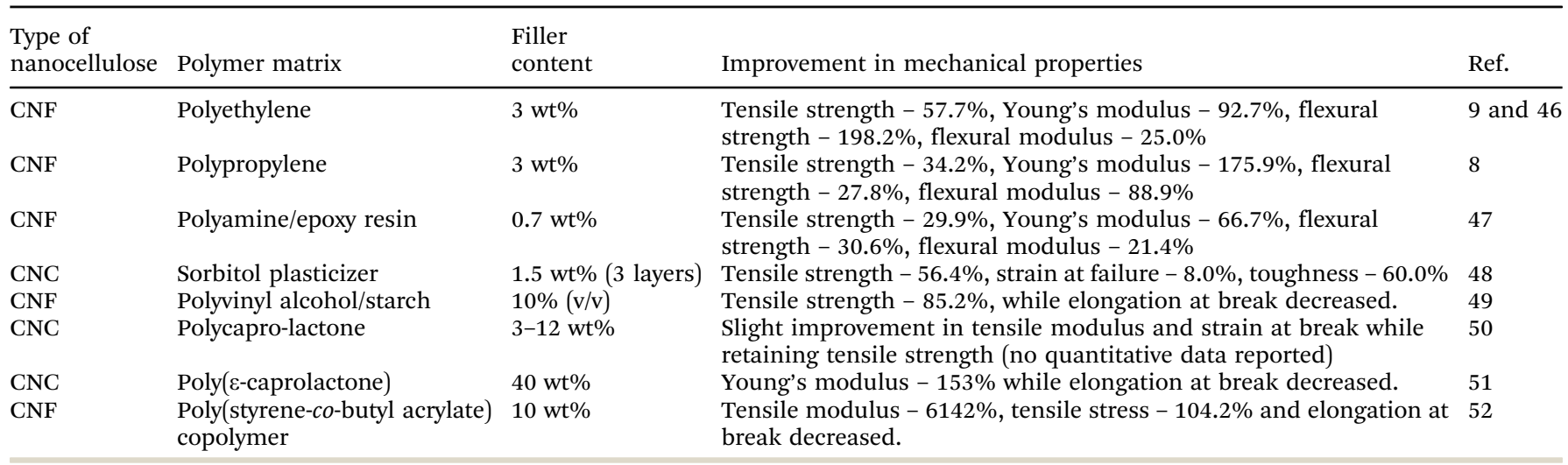

usually added to them. ${ }^{55}$ According to Norrrahim et al. (2018), ${ }^{8}$ the addition of nanocellulose to poly lactic acid has successfully improved the mechanical and thermal stability of the composite material as compared to the neat polymer. Moreover, Montero et al. $(2017)^{56}$ investigated the effect of the addition of CNC into different starch sources (tuber, cereal and legume). They found that the incorporation of $\mathrm{CNC}$ favored plasticization and increased the rigidity of the films formed, as well as their thermal stability and moisture resistance. Panaitescu et al. $(2018)^{57}$ developed a composite material from poly(3-hydroxybutyrate) to which was added nanocellulose and then coated with zinc oxide $(\mathrm{ZnO})$ nanoparticles in order to develop a material with better properties and exhibiting antibacterial activity. It was found that $\mathrm{ZnO}$ plasma treatment completely inhibited the growth of Staphylococcus aureus. Thus, a plasma-treated poly (3-hydroxybutyrate) composite was proposed as a green solution for the food packaging industry.

The properties of nanocellulose which exhibits extremely high specific surface area and crystallinity while having a tuneable surface chemistry gives nanocellulose the ability to sustainably enhance oxygen and water vapor barrier properties when being used as a coating or filler in composites and as a self-standing thin film. ${ }^{58}$ Nair et al. $(2014)^{59}$ reviewed the oxygen permeability and water vapor transmission rate of nanocellulose and other polymers as is shown in Table 3. The use of CNF and CNC in

Table 3 Oxygen permeability and water vapor transmission rate of nanocellulose compared to other polymers

\begin{tabular}{|c|c|c|}
\hline Material & $\begin{array}{l}\text { Oxygen permeability } \\
\text { (cc } \mu \mathrm{m} \mathrm{m}^{-2} \text { day } \mathrm{kPa} \text { ) }\end{array}$ & $\begin{array}{l}\text { Water vapor transmission } \\
\text { rate (WVTR) }\left(\mathrm{g} \mathrm{m}^{-2} \text { day) }\right.\end{array}$ \\
\hline CNF film & 0.6 & $167-234$ \\
\hline $\begin{array}{l}\text { CNF film } \\
\text { (carboxylmethylated) }\end{array}$ & 0.0006 & - \\
\hline $\begin{array}{l}\text { CNF film } \\
\text { (carboxylmethylated) }\end{array}$ & 0.85 & - \\
\hline Cellophane & 0.41 & - \\
\hline $\begin{array}{l}\text { Polyvinylidene } \\
\text { chloride }\end{array}$ & $0.1-3$ & 3.07 \\
\hline Polyvinyl alcohol & 0.20 & - \\
\hline $\begin{array}{l}\text { Ethylene vinyl } \\
\text { alcohol }\end{array}$ & $0.01-0.1$ & - \\
\hline Polyethylene & - & 16.8 \\
\hline Polyvinyl chloride & - & 118.56 \\
\hline
\end{tabular}

films, composites, and coatings has been found to substantially reduce the oxygen permeability and water vapor diffusion of materials containing them. This is due to their size, and swelling constraints formed from the rigid network they form within these films compared to just cellulose fibers. These findings will help in the preservation of many products including various military products such as electronic devices, food and beverages for military field operations and filtration materials that are naturally sensitive towards free oxygen and water.

\subsection{Challenges of nanocellulose application in packaging}

As mentioned earlier, the applications of nanocellulose for several other categories of military packaging have not been explored, therefore extensive research is necessary to enhance the applicability of nanocellulose in military packaging.

The possible effect of nanocellulose including modified nanocellulose on health has recently drawn attention among scientists. Because of that, the safety level of nanocellulose has extensively been evaluated. Research has been carried out to evaluate the potential ecotoxicity, cytotoxicity and genotoxicity of the nanocellulose in packaging applications. Nanocellulose properties differ from their parent bulk materials due to their smaller size, different morphology and larger surface area resulting in their ability to cross natural barriers including electronic and plasmonic effects. ${ }^{60}$ However, nanocellulose is generally known as a safe and non-toxic food substance. Scientists have found that the genotoxic and cytotoxic potential and environmental risk of cellulose-based materials are negligible. Some studies have shown that functionalized nanocellulose is also known to be practically nontoxic. ${ }^{61}$ Moreover, the lack of study on the effect of the modified nanocellulose on the biodegradation capability leads to an urgent necessity of further investigations. Some of the functionalizations of nanocellulose are known to affect the biodegradability of nanocellulose. ${ }^{13}$

\section{Application of nanocellulose in energy devices of the military}

The current rapid rise in economic growth will create additional demands on energy supply. ${ }^{62}$ With the fast development of 
modern society seen presently, there will continue to be a high demand for energy because it is a serious issue in relation to the worldwide power consumption demand. ${ }^{63}$ Various types of modifications have been made by scientists and engineers to address the needs in this area. In the military, there is an everincreasing number of energy devices being used in current and future warfighting systems. For an example, military personnelworn energy devices for various purposes such as surveillance, communication and information sharing include items such as batteries, tactical radios, computers, global positioning system receivers, wearable sensors, power generating devices, power management systems and even weapons.

The aims of the energy application in the military could be more significant in some aspects. For example, the provision of rechargeable devices is an extremely important good to the military as compared to the other conventional purposes. Moreover, technology development regarding materials that can self-generate electrical energy such as solar panels is urgently needed in the military.

Traditionally the production of energy devices is based on plastics, inorganic semiconductors and other petrochemicalbased products. ${ }^{64}$ These raw materials may lead to serious environmental problems because waste generated from these energy devices cannot be degraded naturally. To reduce this issue, researchers have continued to research alternatives to the current materials with the intent to seek more environmentally friendly ones. The relevant industries continue to require newer materials and a revolution in which these sources of energy become affordable, accessible and sustainable into the future. ${ }^{62}$

Recently, nanocellulose has become one of the promising candidate materials for components used in electrochemical energy storage (EES) for a wide range of applications including the military. ${ }^{6,65}$ Due to the interesting characteristics of nanocellulose as has been discussed earlier and through its good and specific electrochemical properties, nanocellulose is a material of interest in emerging energy technologies. ${ }^{64,65}$ The good mechanical properties of nanocellulose can be integrated into composites of polymer electrolytes as a mechanical matrix. Besides that, the unique entangled structure of nanocellulose can be used as a functional scaffold to construct the electrode host, which benefits the transport of ions and achieves excellent cycling performance of the electrodes. ${ }^{66}$

Most of the energy applications of nanocellulose have high requirements for the dispersion stability and uniformity of particles. However, nanocellulose tends to form clusters and aggregates during synthetic and application processes. ${ }^{38}$ As mentioned before, functionalization of nanocellulose is important to increase the dispersity of nanocellulose in polymer matrices. Besides that, since nanocellulose is a nonconductive material, it must be functionalized with conductive polymers, metallic particles or other conductive carbon materials such as graphene, carbon black and carbon nanotubes. There are two ways to functionalize nanocellulose with conductive materials as is shown in Fig. 4. Firstly, it is by coating the conductive material onto a nanocellulose matrix. Secondly, it can be carried out by directly mixing the nanocellulose with conductive materials, which is mainly carried out by in situ polymerization and blending. ${ }^{66}$ The conductive materials such as graphene nano platted have been studied by Erbas et al. (2016) ${ }^{67}$ to identify ways to improve the conductivity of nanocellulose. The results of their study showed that the conductivity of nanocellulose was increased from 0 to $0.75 \mathrm{~S} \mathrm{~cm}^{-1}$.

The modified nanocellulose based EES may be of use in military applications since it has good flexibility, is lightweight and has durability. ${ }^{64}$ Moreover, rechargeable device technology has received much attention from the military especially as the number of electrically powered systems used by the military in operations and in the field has increased. An example of an EES device from nanocellulose is rechargeable lithium-ion batteries, supercapacitors and solar cells. ${ }^{63-65,67,68}$ In this section, the application of nanocellulose for military energy applications is

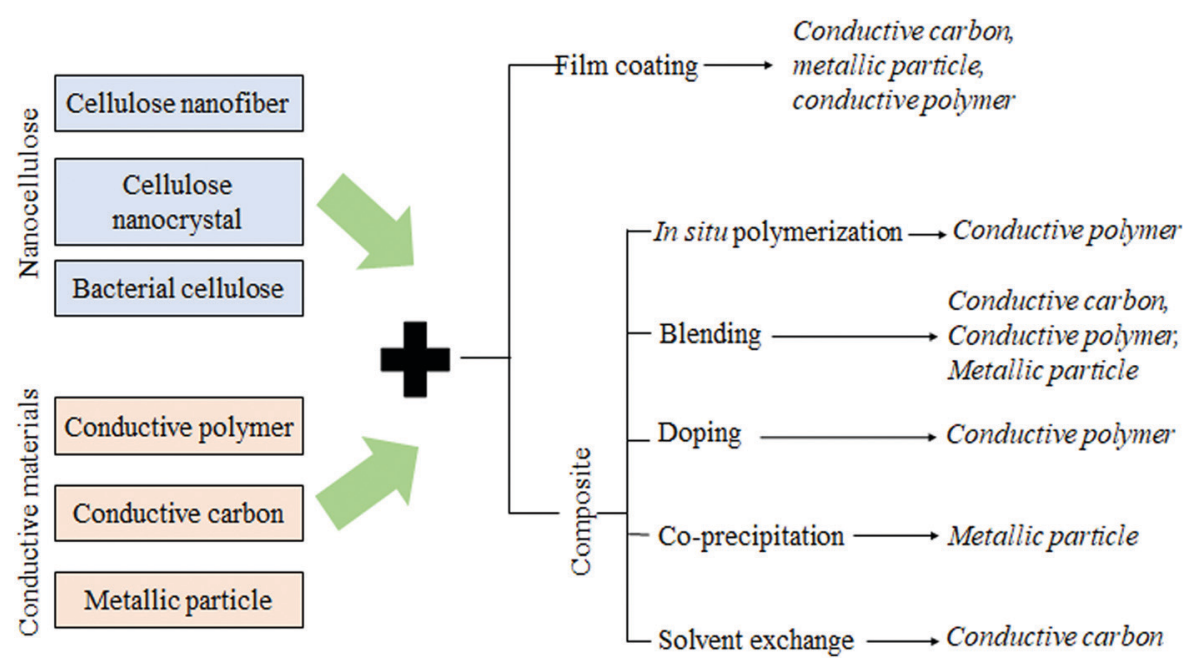

Fig. 4 Schematic illustration of the generalized modification of nanocellulose with conductive materials. Reproduced with permission from ref. 64 . Copyright 2017. Elsevier. 
discussed with focus on the development of supercapacitors, lithium-sulphur batteries and solar energy.

\subsection{Nanocellulose based supercapacitors}

Supercapacitors, also known as electrochemical capacitors, show great promise as a means of meeting the increasingly high power demand owing to their high power density, superior rate capability, rapid charging or discharging rate, long cycle life, simple principles of operation, fast dynamics of charge propagation and low maintenance cost. ${ }^{69,70}$ Supercapacitors normally can be classified as either of two types of capacitor which are electrical double-layer capacitors and pseudocapacitors. Electrical double-layer capacitors function to store energy through electrostatically accumulated charges at the electrode or electrolyte interface while pseudocapacitors are based on rapid redox reactions at the electrodes for a huge pseudocapacitance load. ${ }^{63}$ Nanocellulose can be integrated with active materials or converted to carbon materials as electrode materials for these supercapacitors. $^{63}$

The capacitance of supercapacitors mainly arises from surface reactions of electrode materials, including through electrochemical adsorption/desorption of cations and anions at the electrode/electrolyte interface. ${ }^{70}$ A large specific surface area is favorable for energy storage since it provides more space for electrolyte ion adsorption. ${ }^{64}$ The higher surface area and higher pore volume are presumed to be responsible for the higher specific capacitance. ${ }^{71}$ This porous structure shows great potential as a substrate for flexible supercapacitors through loading with carbon conductive materials, such as carbon nanotubes and graphene oxide, and thus the use of nanocellulose has been widely applied in flexible solid-state supercapacitors of the activated aerogel electrode type. ${ }^{64}$ These supercapacitors have demonstrated good mechanical properties since they have tensile strength of $1 \mathrm{MPa}$ with Young's modulus of $123 \mathrm{MPa}$ compared with traditional supercapacitors. ${ }^{64}$

Research done by Chen and $\mathrm{Hu}(2018)^{65}$ and $\mathrm{Du}$ et al. $(2017)^{64}$ suggested that nanocellulose that has been converted to become supercapacitors which demonstrate both high capacitance (up to $37 \mathrm{mF} \mathrm{cm}^{-1}$ ) and flexibility and can be incorporated into commercial textiles for wearable applications such as in digital or electronic army armor. Despite this excellent flexibility and low cost, the mass loading per length is still relatively low (less than $\left.1 \mathrm{mg} \mathrm{cm}{ }^{-1}\right) .{ }^{65}$ This shows that these materials are an excellent material for military use since the light mass of these materials will be easy to carry on military operations in the field.

\subsection{Nanocellulose based lithium-sulphur batteries}

Battery power is a major factor in military planning due to the increased use of electronics to support modern warfare. The use of current rechargeable Li-ion batteries such as those used by commercial automotive manufacturers not only have insufficient power capabilities for future military vehicle operations but also suffer from serious safety risks due to their use of flammable liquid electrolytes. As a solution to this, lithiumsulphur batteries have been found to be a promising energy storage device with high energy density and low cost. ${ }^{72}$ Huge advances have been made with lithium-sulphur battery technology, which has revolutionized the use of battery-powered electronic gadgets such as laptop computers, smart mobile phones and digital cameras. ${ }^{73}$ The lithium-sulphur battery is a rechargeable battery and since it is portable, it is commonly used in the military in their portable devices or in military vehicles. Several research papers have shown that lithium-sulphur batteries have good promise to begin a new era of long-lasting and high energy batteries for a variety of applications such as in green transportation, for stationary load levelling in intermittent power generation systems of renewable energies such as solar panels or wind mills as well as in space and military applications. ${ }^{72,74}$ They are attractive mainly because of their low self-discharge rate, high cycle life, energy density, and performance. $^{75}$ Traditionally graphite has been used in these batteries as an anode electrode mainly because of its high electrical conductivity $\left(\sim 103 \mathrm{~S} \mathrm{~m}^{-1}\right)$ and theoretical capacity $\left(372 \mathrm{~mA} \mathrm{~h} \mathrm{~g}^{-1}\right) .{ }^{11} \mathrm{~A}$ big disadvantage of the graphite-based electrodes is that they do not have sufficient energy density required to meet today's energy demands and have a higher cost. Nowadays, there has been a growing focus on the use of nanocellulose in such flexible energy storage devices. Fig. 5 shows a conceptual illustration of nanocellulose application in lithium-sulphur batteries.

The nanocellulose polymer electrolyte showed excellent thermal stability $\left(>4200{ }^{\circ} \mathrm{C}\right)$, excellent conductivity $\left(41.2 \mathrm{mS} \mathrm{cm}^{-1}\right)$ and a stable interface towards lithium metal. ${ }^{73}$ It also exhibited a specific capacity of $\approx 100 \mathrm{~mA} \mathrm{~h} \mathrm{~g}{ }^{-1}$ and had stable capacity retention of up to 70 cycles. The internal components of the cell were folded without any mechanical break off thus showing the potential usefulness of nanocellulose as an alternative electrode binder and the feasibility of lithium-sulphur batteries as a new power source. ${ }^{75}$ The stable cycling profiles show that the nanocellulose is an encouraging route towards the realisation of green and reliable next-generation high energy lithium-sulphur batteries. $^{73}$

\subsection{Nanocellulose based solar energy}

Solar cells, which are also known as photovoltaic cells, can convert inexhaustible and clean solar energy into electricity or

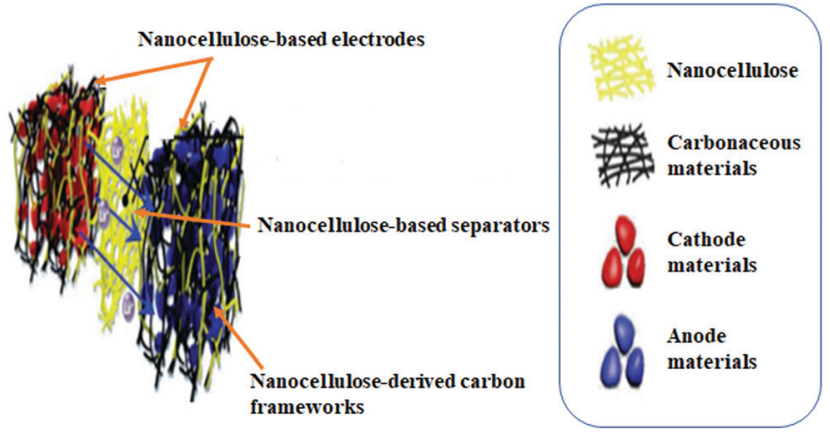

Fig. 5 A conceptual illustration depicting nanocellulose application in lithium-sulphur batteries. Reproduced with permission from ref. 75 . Copyright 2018. Wiley-VCH. 
heat. Nonetheless, the worldwide consumption of solar energy is limited, which is partly due to the high material costs involved with photovoltaics. ${ }^{76}$ This technology has wide applications in the military as a result of its characteristics such as being a safe material with no noise, no pollution characteristics and producing clean energy. ${ }^{77}$ To achieve optimum light scattering and higher absorption in the active materials used for solar cells, high optical haze and transparency characteristics are a must.

Plastics have been widely used in photovoltaic devices since plastic has a low price and has suitable characteristics such as transparency and flexibility. However, there are disadvantages with this material such as it being not environmentally friendly and it is usually not thermally stable. Nanocellulose can be a good alternative to solve this issue since the characteristics of nanocellulose show it has thermal stability, mechanical robustness and is with optical characteristics that are equal to or are superior to plastics. ${ }^{78}$ It is also a novel green substrate for solar cells because of its tuneable physical and chemical performance and has a potentially low cost. ${ }^{76}$ Fig. 6(a) shows a nanocellulose based solar cell power generation system on a military base. According to Lasrado and Ahankari (2020), ${ }^{11}$ silicon and elements from group III-V have been used in solar cells. Unfortunately, the cost of manufacturing solar cells using inorganic materials is very expensive. Nanocellulose is a perfect material to be used to solve this problem since this material is highly suitable for use in high-efficiency conversion devices. $^{11}$
Zhou et al. (2013) ${ }^{79}$ discovered the properties of CNC in solar cells. By referring to Fig. 6(b), the CNC film has the high optical transparency that is necessary for incident sunlight to pass through the substrate and this optical transparency is greatly improved in thinner films. The diameter of some nanocellulose fibrils can be as low as $4 \mathrm{~nm}$, making it an excellent candidate for the production of ultrathin paper solar cells. ${ }^{64}$ Moreover, Fig. 6(c) shows the surface morphology of CNC film and it shows a very smooth surface thus not needing any polishing or surface planarization for solar cell production. There are significant contributions from developing recyclable solar cells using CNC to develop a semi-transparent electrode recyclable solar cell and these solar cells have been found to have a conversion efficiency of $2.7 \%{ }^{79}$ Table 4 shows the efficiency of nanocellulose in the solar cell.

Interestingly, the optical transparency and electrical conductivity of the optically transparent conductive nanocellulose in these solar cells were as high as those in indium tin oxide (ITO) glass that is commonly used in solar cells. ${ }^{80}$ Nanocellulose has already reached a level of performance comparable to that of solar cells fabricated on polyethersulfone (PES) substrates and to that of devices fabricated on ITO-coated glass. ${ }^{83}$ A study by Miettunen et al. (2014) ${ }^{84}$ concluded that the cells fabricated with nanocellulose were as stable as the reference cells in a solar cell and this has been confirmed by stability analysis. Present-day solar cell devices are heavy and cannot be folded, because of the heavy and brittle nature of ITO glass used in their manufacture. ${ }^{80}$ a

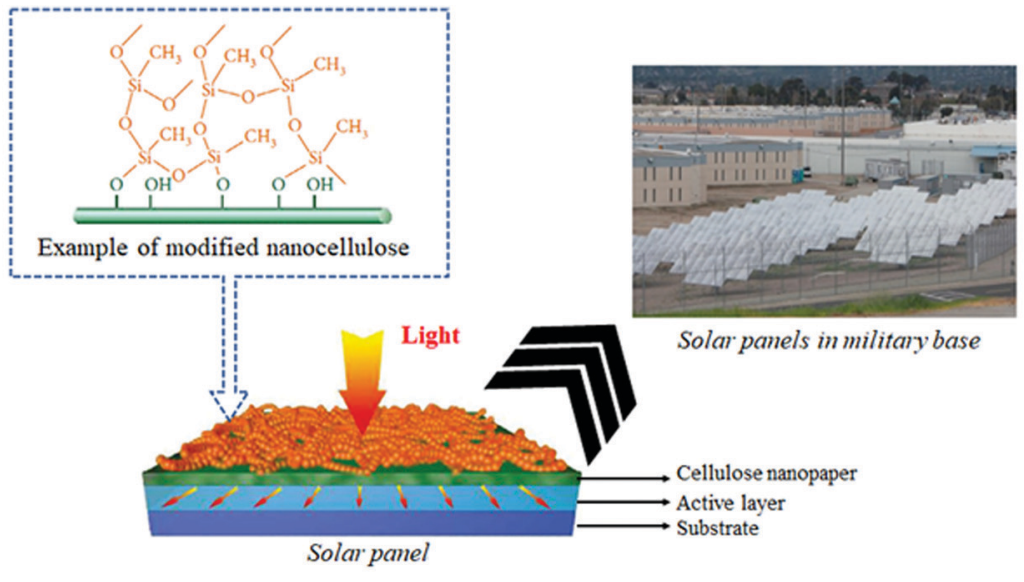

b

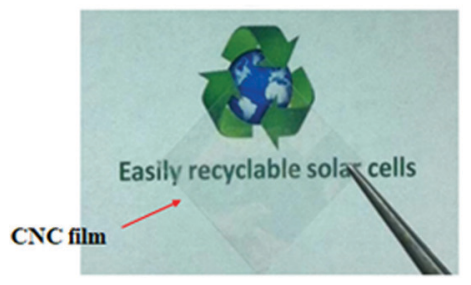

c

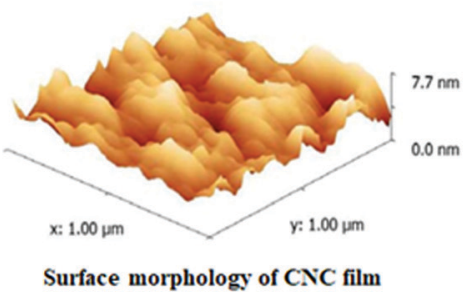

Fig. 6 (a) A photovoltaic power generation system on a military base; (b) a picture of the CNC film on top of paper to demonstrate its transparency; (c) an atomic force microscopy image of the surface of a CNC film. This figure was redrawn and adapted from ref. 11,77 and 79. 
Table 4 Comparison of different types of nanocellulose as solar cells and the efficiency of these solar cells

\begin{tabular}{lllcr}
\hline $\begin{array}{l}\text { Type of } \\
\text { nanocellulose }\end{array}$ & Function of nanocellulose & Type of solar cell & $\begin{array}{l}\text { Output solar cell } \\
\left(\mathrm{mA} \mathrm{cm}^{-2}\right)\end{array}$ & $\begin{array}{l}\text { Solar cell } \\
\text { efficiency (\%) }\end{array}$ \\
\hline CNF & Conductive and transparent substrate & Organic solar cell & 9.58 & 3.2 \\
CNC & Substrate & Organic solar cell & 7.5 & 8.7 \\
CNC & Substrate & Organic solar cell & 3.5 & 7.5 \\
BNC & Solar cell encapsulating films & Organic solar cell & - & 7.3 \\
CNC & Substrate & Organic solar cell & 7.3 & 8.8 \\
CNF & Electrolyte & Dye-sensitized solar cell & 11.7 & 82 \\
& & & 83 \\
\end{tabular}

\subsection{Challenges of nanocellulose application in energy devices}

Despite the great progress achieved in nanocellulose used for energy, continuous efforts are needed to improve the current application, including (1) to improve the device manufacturing process that can be easily scaled up, (2) to develop a stable and highly conductive solid-state electrolyte to improve the energy density and safety of the devices for practical applications, and (3) advanced integration techniques to make highly integrated, flexible and multifunctional energy devices. ${ }^{85}$

In the nanocellulose based composite production for energy devices, it is important to be noted that nanocellulose is extremely difficult to disperse in polymers due to their intermolecular interactions. It remains a challenge to optimize its dispersion. Many scientists have focused their research to improve the dispersion of nanocellulose in composite matrices. In situ polymerization and post-polymerization compounding are two commonly used methods utilized to incorporate nanocellulose into polymer matrices. ${ }^{11}$ However, these techniques also come with several problems such as only water-soluble polymer matrices being applicable.

Besides that, in the manufacturing of such composites, film casting is not an industry-scale process. To produce nanocellulose composites for commercial purposes, a processing technique must allow manufacturing of these materials from the laboratory to an industrially viable method. The processing techniques like extrusion and injection molding are very promising as they are very economical, simple, green and do not require organic solvents. More studies are required to investigate the effect of aspect ratio that reduces the composite performance due to shear forces offered by the screws.

With addressing these remaining challenges, ubiquitous applications of nanocellulose-based energy devices with low cost and high energy density in electronic devices of the military are anticipated in the near future.

\section{Applications of nanocellulose as a fire-retardant material in the military}

Many polymeric materials that are commonly used in the military are potential fire hazards and so flame retardants are very often incorporated into them to limit their flammability. In the military, development of fire-retardant materials that can resist explosion is generally important as compared to other commercial applications of fire-retardant materials. Moreover, high mechanical strength fire-retardant materials are also needed in the military. Fire-retardant materials can be applied in several applications in the military such as building materials, army uniforms, helmets, weapons, fighter jets and also for other vehicles. The R\&D in this area continues to develop new durable fire-retardant materials to meet military needs. Rigid polyurethane (PU) is the most common material used in the field of construction insulation and in transportation assets of the military. This is because PU has several excellent properties, which include being light-weight, having high compressive strength, low thermal conductivity, good cohesiveness, and low water absorption. ${ }^{86}$ However, pure PU itself is flammable, which limits its applicability. In order to avoid the fire hazard caused by PU, it is usually combined with fire-retardant additives to constitute a flame retarded PU composite when applied in the manufacture of products.

The development of fire retardant nanocellulose composites is becoming more common in advanced engineering applications. The flammability characteristics of nanocellulose-reinforced thermoset nanocomposites have been explored and they have shown promising results. Nanocellulose composites provide a high level of fire safety such as producing little smoke and reduced toxic gas production when exposed to fire. In this way, they are able to protect various novel military products, infrastructure and the environment, and mainly aid in preventing loss of lives to fire. ${ }^{87}$ To achieve this, these additives or fillers called flame retardants, such as halogens, boric acid, phosphorus, minerals and nanometric compounds are incorporated into nanocellulose composites to prevent or minimise fire from causing damage. Solution impregnation and surface treatment are methods of incorporating the fire-retardant agents with the nanocellulose. In some cases, composites of nanocellulose have been added to polyurethane to make it into a fire retardant material. ${ }^{86}$ Table 5 summarizes examples of fire-retardant materials developed from nanocellulose composites.

\subsection{Challenges of nanocellulose as fire-retardant materials}

In developing nanocellulose based fire-retardant materials for the military, some challenges related to stability and hydrophilicity are the main concerns. Dispersion of nanocellulose in polymer matrices is also the main problem. To overcome the dispersion problem, several efforts can be carried out by introducing suitable compatibilizers or functionalizing the nanocellulose. Besides that, fire-retardant materials in the military are demanded to be suitable for several niche environment conditions, especially during the conflict zone. Nanocellulose is known as a biodegradable material, and thus modification on this nanocellulose-based fire-retardant is important. Scientists 
Table 5 Examples of nanocellulose-fire retardant composites

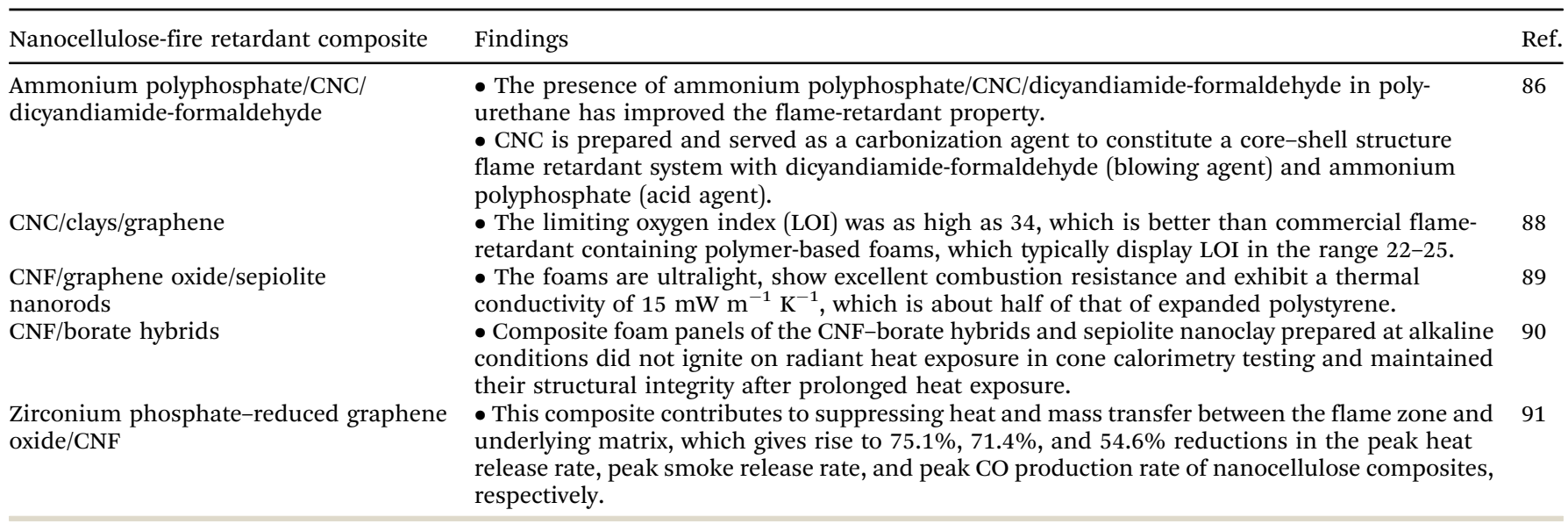

have shown that the functionalized nanocellulose can reduce its biodegradability. ${ }^{13}$ Moreover, the high moisture adsorption of nanocellulose limits the storage capability and can reduce the performance of the developed nanocellulose based fire-retardant materials. The hydrophilicity characteristic of nanocellulose can also be modified by functionalization to make it a superhydrophobic material. To the best of our knowledge, there is a lack of research focused on these several issues as mentioned here.

\section{Applications of nanocellulose in military propellants}

Energetic compounds are defined as the active chemical components of explosives and propellants, and are necessary both for commercial (e.g., demolition and mining) and military purposes. ${ }^{92}$ Propellants can be described as an explosive material for propelling projectiles, fuel plus oxidizer for rocket engines and gas that is kept under pressure in a container or can expel the ingredients when the pressure is released. It may be in the form of gas, liquid, plasma or as a solid. Table 6 lists a few types of propellants used in various applications. Differing from the commercial types of propellants, the military propellants are generally insensitive, low characteristic signal, high-energy, high-burning-rate, fuel-rich and anti-high overload.

In order to have a higher energy per unit mass than current explosives, nanocellulose can be used in the development of military propellants. Functionalization is a key factor for success for nanocellulose as a good propellant. There are several examples of R\&D carried out on the development of nanocellulose as a propellant. Zhang et al. $(2016)^{101}$ fabricated a double-base solid propellant using nanocellulose as a filler. The CNF used was extracted from wood cellulose. Due to its hydrophilic property, high aspect ratio and good suspension stability, their performance as a double-base propellant was significantly improved as compared to conventional double base propellants. The tensile strength and elongation at break were notably increased by nearly $34 \%$ and $45 \%$ respectively, while the burning rate of the propellant was increased by $27.5 \%$ and the pressure coefficient decreased by $20 \%$.

Table 6 Types of propellants for various applications

\begin{tabular}{|c|c|}
\hline Type of propellant & Composition \\
\hline JP-8 & $\begin{array}{l}\text { - } 18 \% \text { aromatic hydrocarbon, } 82 \% \text { aliphatic } \\
\text { hydrocarbon, and kerosene-based fuel }\end{array}$ \\
\hline Jet $\mathrm{A}$ and Jet A-1 & $\begin{array}{l}-18 \% \text { aromatic hydrocarbon, } 82 \% \text { aliphatic } \\
\text { hydrocarbon, and kerosene-based fuel }\end{array}$ \\
\hline $\begin{array}{l}\text { Micro-electromechanical } \\
\text { systems (solid) }\end{array}$ & $\begin{array}{l}\text { - Zirconium perchlorate potassium mixture } \\
\text { propellant (glycidyle azide polymer mixed with } \\
\text { ammonium perchlorate and zirconium) }\end{array}$ \\
\hline Cryogenic & $\begin{array}{l}\text { - Gases chilled to subfreezing temperature and } \\
\text { condensed to form a combustible liquid such as } \\
\text { liquid oxygen and liquid hydrogen }\end{array}$ \\
\hline Chemical & $\begin{array}{l}\text { - Modified bacteria like Escherichia coli and } \\
\text { Pseudomonas for butanetriol production }\end{array}$ \\
\hline Gas & - Krypton and xenon \\
\hline
\end{tabular}

Solid (rocket)
- Aluminium, magnesium, boron, their alloys and composites

- Metal hydrides

- Oxidizer: ammonium perchlorate (AP)

- Fuel: hydroxyl-terminated polybutadiene (HTPB)
Application

Ref.

- Military aircraft-must have military additives including static electricity, corrosion, and icing inhibitors, thermal stability enhancer and antioxidants

- Commercial airlines

93

- Micro-spacecraft and many other low-cost miniature 95 space system

- Large rockets and NASA's space shuttle

96

- Missiles

- Can be used in rotating propellant supply mode hall 97 thrusters

- Strap-on boosters, launch vehicles for low earth orbit 98 and 99 (LEO) payloads and tactical missiles

- Solid rocket motors 
Moreover, Yan et al. $(2012)^{102}$ synthesized thermite-based nitro-nanocellulose integrated with nano-aluminium using a one-step electrospinning process to enhance the energy release of the propellant caused by the acceleration of oxidation kinetics and a specific impulse. Thermite-based nitronanocellulose showed a higher flame propagation rate and fast reaction kinetics in their combustion tests, which corresponded to the mass loading of nanothermite within the binder of the nanofibers. The electrospinning method has become a solution for problems related to melting and casting of nanometalized propellants. Besides that, Jamal et al. $(2020)^{103}$ developed nitrocellulose from BNC using a nitration method for utilisation as a gun propellant. They managed to synthesise a high percentage of nitrogen content. Based on the characterisation results, 60 minutes of reaction time was the optimum time for the production of a high percentage of nitrogen content.

\subsection{Challenges of nanocellulose application as a propellant}

Due to the semi-rigid nature of nanocellulose, nanocellulosebased propellants have the drawback of high-temperature softening and low-temperature embrittlement. ${ }^{101}$ The balance of energy and mechanical properties of nanocellulose-based propellants is difficult to achieve, and yet possible. The new requirement of modified nanocellulose based propellants is to improve their mechanical properties as well as to retain their energy. The effect of nanocellulose on the properties of composites is influenced by the dispersion and the compatibility of nanocellulose in the matrix. Suitable functionalization will improve the compatibility of nanocellulose with the polymer matrix of the propellant. Similar to nanocellulose as a fire-retardant material, development of superhydrophobic nanocellulose-based propellants is necessary. This is because high moisture adsorption of nanocellulose limits the storage capability and could reduce the performance of the developed nanocellulose based propellants.

\section{Applications of nanocellulose as filtration materials in the military}

Development of filtration materials is one of the fastestgrowing technologies in this century. Water and air treatment applications in particular, have received significant commercial and military attention. Commercial application of filtration materials has been used widely in respiratory filters such as N95, N99, N100, surgical masks and also for home air and water filters. Meanwhile, filtration materials are generally used for military masks, filter cartridges, portable survival water filters and military vehicle air filters. Development of filtration materials for the military requires broad functionalities. This is because, in the conflict zone, the army is exposed to a variety of rare types of biological and chemical contaminants. Meanwhile, the development of filtration materials for commercial purposes is more specific to the known types of contaminant. There are several approaches developed to address arguably one of the largest problems that humanity has been confronted with in the 21st century, which is clean water. ${ }^{104,105}$ Chemical and biological contaminants in water from foreign agents such as heavy metals, organic and inorganic compounds, and microbes have not only seriously affected the environment but also threaten the military operations especially in the field. In this regard, the treatment of chemically and biologically contaminated air and water is a matter of very serious concern to the military. These two contaminants are discussed below.

\subsection{Chemical contaminants}

There have been several types of chemical compounds developed into agents or weapons for warfare such as toxic gases, nuclear reactive compounds, and nerve agents. During World War I, a variety of toxic gases were developed and used in warfare such as a number of tear gases, gaseous chlorine, phosgene and mustard gas. Beyond that, organophosphorus compounds, which are highly toxic synthetic compounds, were originally developed as pesticides and then developed to become warfare nerve agents such as tabun, soman, sarin, and VX. ${ }^{106,107}$ Nowadays, organophosphate pesticides are a frequent cause of admission of people (mostly farmers) to hospitals in developing countries (about 3000000 acute intoxications have been reported annually world-wide). Moreover, heavy metal contamination in the environment arising from industrialisation activities such as mercury, arsenic, cadmium and cobalt is a huge concern especially in areas of conflict and as a consequence of military action in those areas. Heavy metals are known to cause serious deleterious health effects on humans, animals and plants.

Activated carbon and zeolites have been used as, and are the most popular adsorbents for the removal of chemical contaminants from waste effluents as well as from the atmosphere. ${ }^{13,108-110}$ However, these materials have restricted applicability because of their non-renewable physical form and high costs especially for activated carbons which will suffer from material losses during regeneration processes. ${ }^{111}$

A combination of biosorption and nanotechnology offers a new and greener way to remediate these contaminants. Hence, nanocellulose has been identified as an excellent filtration material against chemical contaminants. It has already been proven to have higher adsorption capacity and be a better filtration barrier compared to other similar materials at the macroscale. Its high specific surface area that will enable the adsorption of various atoms, ions, and molecules and the abundance of hydroxyl groups within leads to potential functionalization of this material for decontamination purposes. ${ }^{112,113}$ Several R\&D papers have shown the effectiveness of nanocellulose in the remediation of chemical contaminants and these are shown in Table 7. The development of nanocellulose based filtration materials can be applied to products such as face mask cartridges, water filters and air filters which are used by the military.

\subsection{Biological contaminants}

Biological weapons are microorganisms such as viruses, bacteria, fungi, or toxins that are produced and released deliberately to cause disease and death in humans, animals or plants. According to Frischknecht et al. (2003), ${ }^{117}$ there are two international treaties which have banned the use of biological weapons, the first in 1925 
Table 7 Remediation of chemical contaminants by nanocellulose

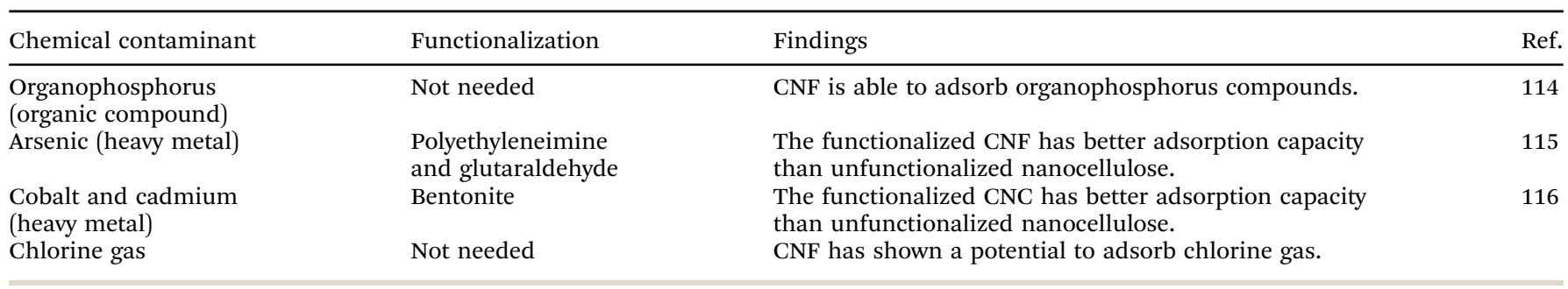

and then again later in 1972, but they have largely failed to stop countries from conducting biological weapon research and to prevent large-scale production of biological weapons. With greater awareness of the biology of disease-causing agents such as viruses and bacteria as well as the availability of biological toxins, this has given rise to the fear that modified pathogens from these organisms and toxins could become devastating agents for biological warfare especially since genetic manipulation techniques have become more available in the last decade. Besides that, the threat of virus epidemics such as the 1918 influenza pandemic, the various avian flu outbreaks and the current COVID-19 pandemic is a matter of serious international concern as these epidemics have caused millions of people to fall ill and even die from them. This problem is aggravated by the occurrence of mutations, some occurring frequently, which has a negative impact on the development of efficient vaccines against these viruses. Therefore, in order to minimize the health impact on populations affected by these epidemics, efficient, robust and affordable virus removal filters are in high demand to help prevent the further spread of viruses in hospitals, transportation hubs, schools, or other venues with high human traffic or contact and this also includes both areas afflicted by military conflicts and those under threat of natural and man-made disasters. Table 8 shows examples of agents used as or developed for biological warfare.

Therefore, it is imperative that the development of materials that have excellent adsorption capacity towards biological warfare agents is pursued urgently. As has been found when used against chemical contaminants, nanocellulose offers several interesting

Table 8 Examples of the development and use of biological warfare agents $^{117}$

\begin{tabular}{lll}
\hline Disease & Pathogen & Used in \\
\hline Anthrax & Bacillus anthracis & $\begin{array}{l}\text { World War I } \\
\text { World War II } \\
\text { Soviet Union, 1979 } \\
\text { Japan, 1995 } \\
\text { USA, 2001 }\end{array}$ \\
Botulism & $\begin{array}{l}\text { Clostridium } \\
\text { botulinum }\end{array}$ & - \\
Haemorrhagic & $\begin{array}{l}\text { Marburg virus } \\
\text { fever }\end{array}$ & Soviet bioweapons programme \\
Plague & $\begin{array}{l}\text { Arena viruses } \\
\text { Yersinia pestis }\end{array}$ & - \\
Smallpox & Fourteenth-century Europe \\
Tularemia & Francisella & $\begin{array}{l}\text { World War II } \\
\text { Eighteenth-century North } \\
\text { America }\end{array}$ \\
& World War II
\end{tabular}

features as a filtration material against biological contaminants. Its high specific surface area enables the adsorption of various microbial cells, and the porous nature of nanocellulose materials can separate various molecules and retain certain microbially derived objects. Several R\&D reports have shown the effectiveness of nanocellulose in the remediation of biological contaminants and these are shown in Table 9. The development of nanocellulose based filtration materials can thus be applied to current filter materials used in the fabrication of face mask filter cartridges, water filters, and air filters, especially those used in industry and by the military.

\subsection{Challenges of nanocellulose application as a filtration material}

Several challenges related to the development of nanocellulose as filtration materials need to be considered. The filtration and adsorption efficiency of nanocellulose towards several types of chemical warfare agents and toxic gases as listed above have not been fully explored. Therefore, future research on the application of nanocellulose in filtration materials of the military can be focused on those compounds.

Nanocellulose has a high tendency to self-aggregate through hydrogen bonding..$^{13}$ This will reduce the available adsorption sites and limit their reabsorption capability. One of the alternatives to this issue is to produce a nanocellulose aerogel. Moreover, the chemical modification of nanocellulose, which is often a prerequisite to boost the adsorption capacity, is expected to reduce and even to inhibit its biological degradation. The presence of chemical functionality on the top layer of the cellulose fibrils is likely to limit the accessibility of bacteria to the core of the cellulose backbone, preventing the proliferation of bacteria on the nanocellulose.

Scientists also continue to discover ways to increase the adsorption capacity of a range of pollutant species to be absorbed through target chemical modification of the nanocellulose. Further modification on nanocellulose is needed in order to make this material capable of multi-pollutant removal. Contaminants in real water are typically very complicated, and various types of contaminants usually coexist. The co-removal of multiple types of coexisting pollutants might be possible if multiple adsorption sites are available on the adsorbent.

\section{Applications of nanocellulose in military textiles}

The textile industry is also looking to use technology in order to create more scientific clothing, like antimicrobial, fire-retardant, 
Table 9 Remediation of biological contaminants by nanocellulose

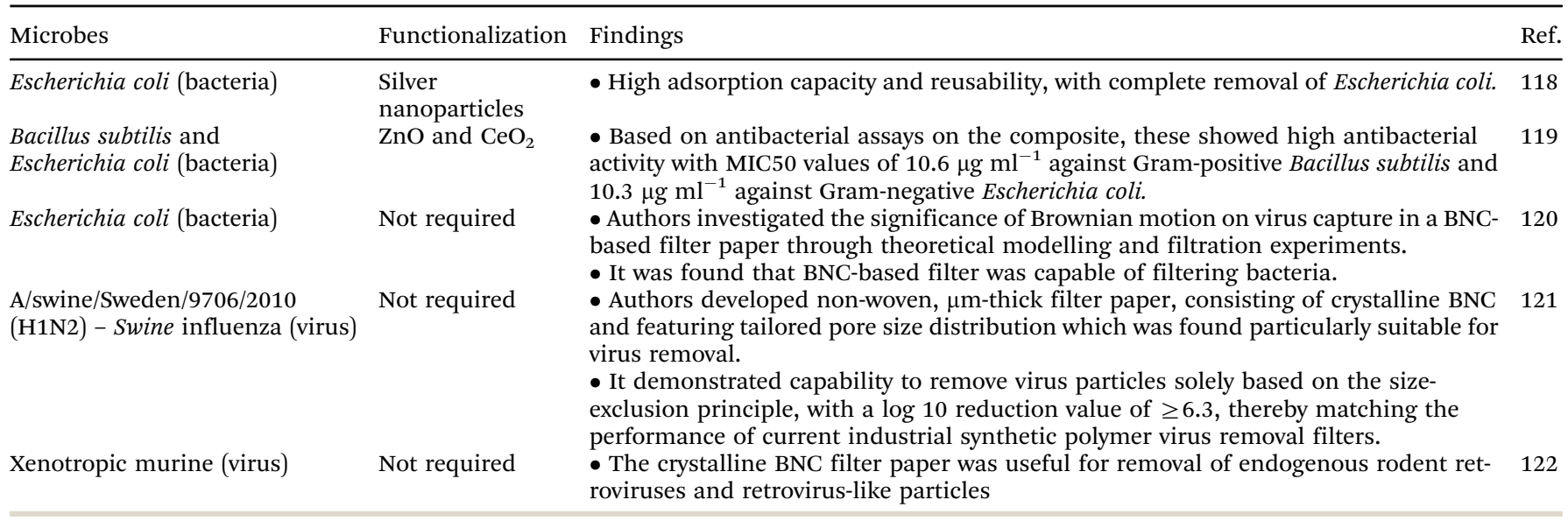

self-cleaning and good water and air permeability. Product advancements in the textile industry have covered a wide range of commercial and military areas. The aims of these areas might be slightly different. For military purposes, development of hydrophobic, high strength and fire-retardant textiles is more prominent. Meanwhile, a color-adaptive and an anti-wrinkle textile receive more attention from the commercial industries.

Textiles are major components of military equipment, and their use includes a wide variety of functionalities. The examples of textiles in the military include combat uniforms, tents, shelters, parachutes, sails, aeroplane materials, safety harnesses, body armour, explosive ordnance disposal bomb suits, sandbags, fire resistance materials, footwear, camouflage systems and many more. ${ }^{123,124}$ Through several innovations with smart textiles, nanotechnology-enabled apparel that can protect military personnel from pathogens, toxic gases and other hazardous substances has been developed. Moreover, it could also allow for the constant monitoring of body functions of personnel wearing these smart textiles. Ngo et al. (2014) ${ }^{125}$ presented several criteria for nanotechnology which is used for application in the textile industry and these are shown below:

(1) self-cleaning and dirt-free textiles;

(2) medical textiles that have an anti-microbial function;

(3) military textiles that are capable of minimizing accidents, injuries and infections;

(4) automotive textiles that have antiallergy, antistatic, improved wear and tear resistance and are self-cleaning; and

(5) smart textiles which when combined with an electronic device allow body vital signs to be monitored.

The choice and design of textiles to be used for the fabrication of military equipment is challenging. There are several important characteristics which are related to the environments where the textile will be used that are important, these are thermal protection, good durability, water repellent, able to withstand static propensity in numerous applications, able to endure tears and breaks, able to protect from ballistic injury and resistance towards chemical and biological threats. ${ }^{126-128}$ For example, during desert operations, crew of military battle tanks and armored vehicles puts themselves at a high risk of heat stroke and dehydration because of the working environment within these vehicles especially under combat conditions where the crews have to operate their vehicles efficiently and effectively even when closed up within the vehicles for long periods of time. The risks of heat stress on the crew which can affect the effectiveness of operations include hyperthermia, reduced mental-alertness, occurrence of seizures and occurrence of reduced situational awareness from physical discomfort. On the other hand, with troops involved with arctic and mountainous operations, they are at risk of UV-blindness, hypothermia and hypoxia. ${ }^{129}$ All these effects can lead to morbidity and mortality if no action is taken to improve the technology of textiles used by the military.

Nanocellulose has been applied in modern textiles to provide several benefits as mentioned earlier. ${ }^{130-132}$ Since it has certain superior properties compared to current materials such as Kevlar, nanocellulose can be useful for uses such as thermal insulation, sanitary napkins, tampons, diapers or as wound dressings. ${ }^{133}$ Several innovations have been discovered in this area. Mishra et al. $(2014)^{133}$ discussed in their review the numerous applications of nanocellulose in the textile industry suitable for the production of lightweight body armor and ballistic glass. As shown in Fig. 7, body armor used by the military requires certain special characteristics, which are high mechanical strength, light-weight, hydrophobic, antimicrobial and anti-ballistic. Nanocellulose can be a great alternative to the current material used for body armor which is Kevlar.

Safety glazing is one of the most important methods of preventing the release of glass fragments during transport collisions which can then cause physical injuries. This extends to protective personal equipment such as face shields and goggles which are used by personnel responding to threats such as natural disasters, terrorist attacks and civil unrest. Basically, to ensure the safety of personnel, material to protect vision involves the use if poly(vinyl butyl) (PVB) that is sandwiched between two (or more) glass sheets. The use of PVB is because of its transparent property and its ability to keep broken pieces of glass in place. However, this polymer is expensive, heavy and requires a certain thickness to work. Its 

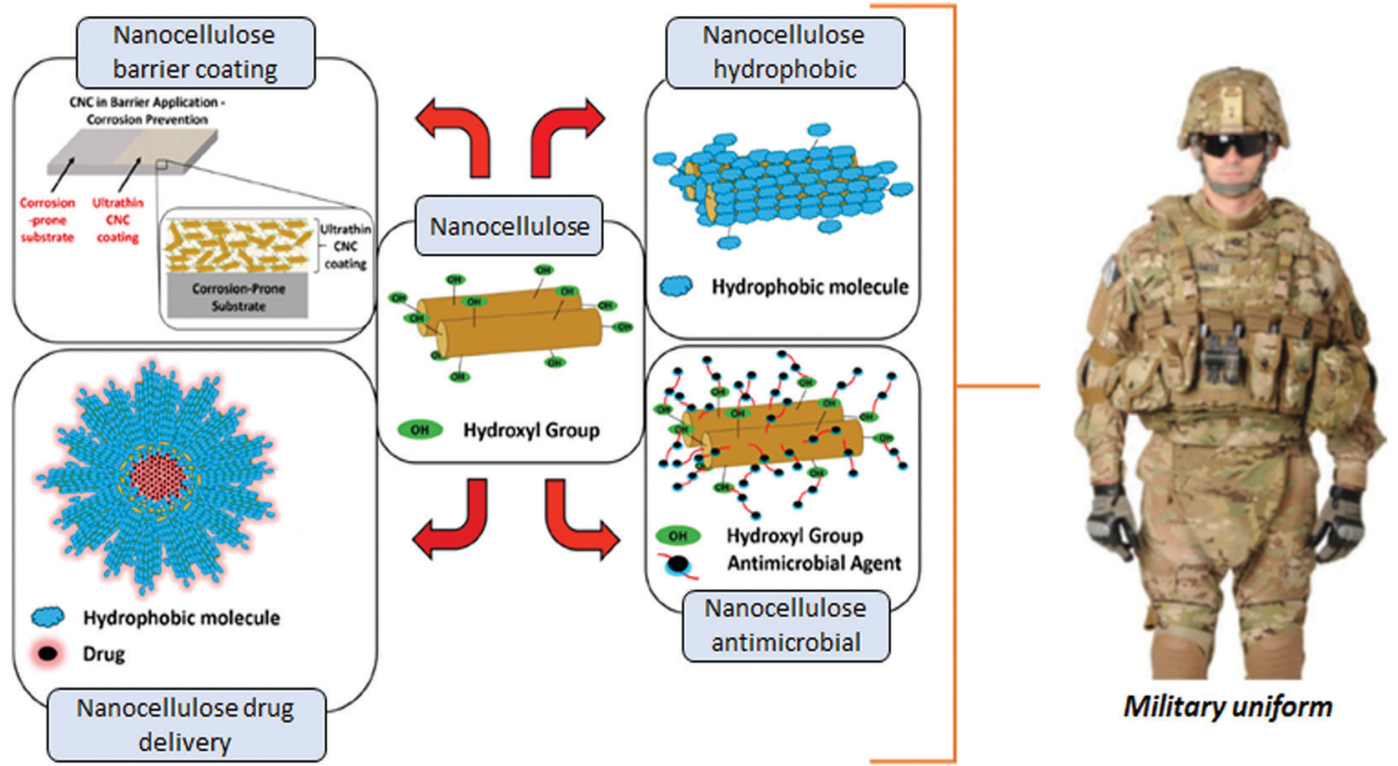

Fig. 7 Nanocellulose in military uniform. This figure was redrawn and adapted from ref. 134 and 135 .

use can also reduce vision quality and affect transparency of the glass it is layered with. Maury et al. (2019) ${ }^{136}$ mixed PVB with nanocellulose using hot pressing techniques to overcome the drawbacks of PVB. They showed that the composites had promising properties with low surface mass, good transparency and improved mechanical properties. Steele et al. $(2012)^{137}$ used poly(methyl methacrylate) incorporated with nanocellulose of varying crystallinity, fiber size and surface functionalization to improve its transparency properties. This epoxy resin was prepared using two techniques which were a freeze-drying technique to form an aerogel and a sol-gel technique by exchanging solvent with epoxy. Aerogel samples showed improved mechanical properties, but the transparency was reduced due to agglomerations in the material matrix. Meanwhile, the sol-gel method displayed good mechanical properties, however, not as good as with the aerogel samples. The transparency performance was better in the sol-gel technique. ${ }^{137}$ Toha et al. $(2018)^{138}$ discovered that the inclusion of CNF from rice straw in laminated cellulose created a material that had superior properties compared to Kevlar reinforced epoxy resin. These new reinforced composites were prepared using a hand lay-up technique to improve the mechanical properties of these composites. The laminated composite materials produced were found to have high strength, were lightweight and exhibited high stress-strain resistance as compared to Kevlar/epoxy only composites.

In the military, superhydrophobic nanocellulose-based textiles have an immense potential in many applications. During a military conflict, while carrying out their missions, soldiers cannot avoid getting their uniforms wet and dirty. To remove dirt contaminants and water from the surface of their clothing and other appliance materials, modification becomes a higher priority. According to Wei et al. $(2020),{ }^{139}$ there are two factors in fabricating a superhydrophobic nanocellulose: the appropriate hierarchical structure with durable nanoparticles and low energy surface. The most common methods for preparing robust superhydrophobic textile surfaces are dip-coating, wet chemical deposition, electro-assisted chemical deposition, spray coating, sol-gel, chemical etching, chemical vapor deposition, plasma processing and polymer grafting.

Applications of electronic textiles in the military have been well discussed by Nayak et al. (2015) ${ }^{140}$ These electronic textiles can be used in monitoring personnel health (blood pressure, heartbeat, body temperature), locating soldiers, for communications and in environmental temperature monitoring. As described before, the functionalization of nanocellulose has successfully made these textile materials good conductive agents. ${ }^{141}$ There are a few types of electronic textiles for military applications where most of them use electrical impulses as an output signal. For example, acoustic type materials can be used for the detection of unrecognized vehicles, enemies or aircraft when they are approaching, while buttons or optical detectors which use infrared signals can be used to detect the location of gunshots. ${ }^{140}$ Fig. 8 shows the application of modified nanocellulose in electronic textiles in the military. Nechyphorchuk et al. $(2017)^{142}$ developed woven cotton fabrics using CNF mixed with plasticizers suitable for printing or dyeing using (1) conventional colored water-based inks and (2) conductive silver nanoparticle inks. The presence of CNF helped the inks to settle onto the substrate, which ensured good quality with faster printing speed production. Furthermore, the CNF coating allowed for a conductive layer, which maintained their electric signal even when being folded.

\subsection{Challenges of nanocellulose applications in textiles}

The versatility of nanocellulose functionalization can be the future of sustainable, biocompatible, and biodegradable materials for a variety of applications in military textiles. However, the 


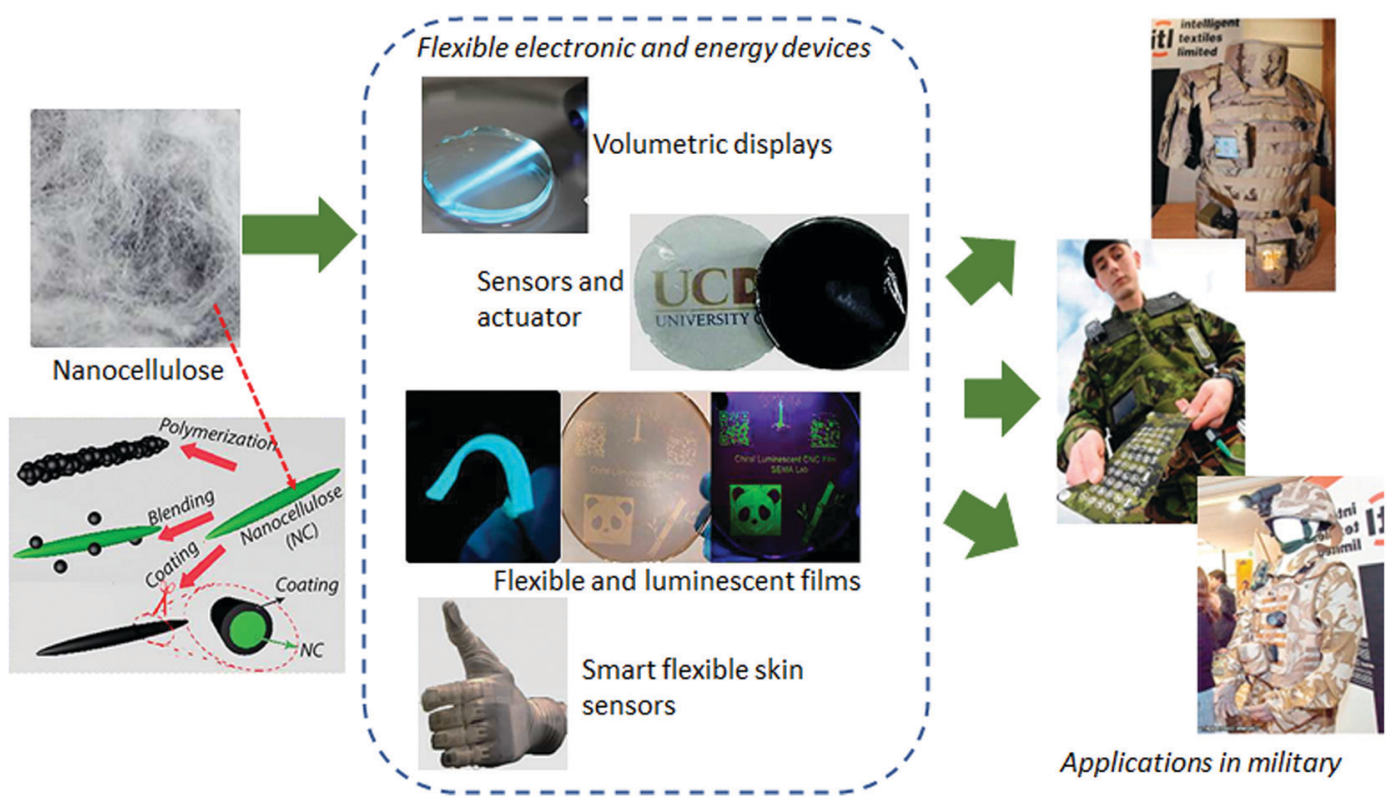

Fig. 8 Military uniforms with a wearable computer and keyboard. This figure was redrawn and adapted from ref. 140 and 143.

reality is that most nanocellulose modifications involve aggressive pretreatments. ${ }^{134}$ This usually affects its structural integrity and crystallinity, which could subsequently alter its mechanical properties. Therefore, new and less aggressive modification processes and chemicals need to be developed. Moreover, some of the toxic chemical compounds are easy to adsorb by a human. Many research studies have to be carried out to evaluate the potential ecotoxicity, cytotoxicity and genotoxicity of the functionalized nanocellulose in textiles.

\section{Applications of nanocellulose for military medical purposes}

Nanotechnology is extensively studied in many medical applications including in the military. Military physicians have played a role in nearly every major modern medical advancement. Several major reforms could significantly improve the quality of health care, especially in the military. This includes discovering new advanced materials that could improve the current methods and means of treatment in medicine. In the military, extensive research on the medical application of nanocellulose can be more focused on drug delivery, antimicrobial membranes and skin tissue development. This is because those listed areas are really important especially during conflict times and war zones. For example, the delivery of drugs such as antidotes needs to be carried out immediately after the army has been exposed to nerve agents. Besides that, an effective antimicrobial membrane must be applied directly to the injured army for healing the wounds before receiving further treatment in the hospital.

In the past decade, there has been an increasing interest in the use of nanocellulose in medicine. ${ }^{144,145}$ Generally, nanocellulose has already been widely used in various medical fields

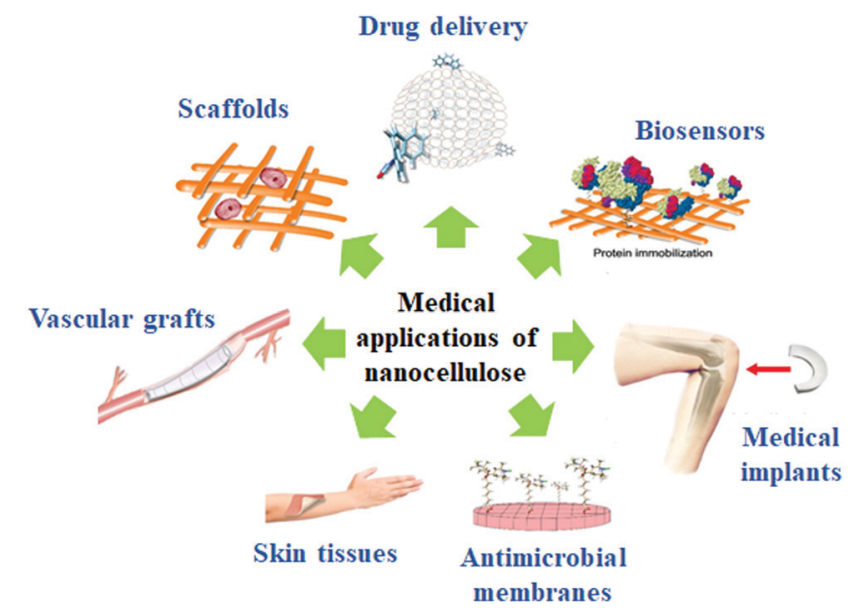

Fig. 9 Medical applications of nanocellulose. (C) 2015 John Rojas, Mauricio Bedoya and Yhors Ciro. Reproduced from Rojas et al. (2015); ${ }^{146}$ originally published under Creative Commons Attribution 3.0 License Available from: DOI: $10.5772 / 61334$

such as tissue engineering, as a bone scaffold, for wound healing, and drug delivery as is shown in Fig. 9. However, in this section, only those applications that relate to the military are reviewed.

\subsection{Organ reconstitution and tissue regeneration}

Organ reconstitution and tissue regeneration have been the primary goals of tissue engineering, especially in military medicine. Virtually every tissue in the body is of military importance due to the diverse nature of injuries associated with war and conflict. ${ }^{147}$ In order to treat tissue and organ defects arising from injuries sustained from kinetic and blast injuries, synthetic substitutes can be created which act to replace or repair the damaged organs and tissues. 3D scaffolds 
are used in tissue engineering as an artificial extracellular matrix for cell seeding, proliferation and new tissue formation. These scaffolds can be prepared in several ways, such as by electrospinning, freeze-drying, 3D printing and solvent casting. ${ }^{148}$ The advantages of nanocellulose and other biopolymers for use as scaffolds are the biological recognition they possess, that may positively support cell adhesion and function. The scaffold eventually should biodegrade naturally in the body at the same rate as new tissue grows, and subsequently, be safely eliminated from the body. The nanocellulose scaffolds present all the requirements for tissue engineering technology, such as possessing superior water absorption, water retention, biocompatibility and mechanical properties.

\subsection{Medical implants}

Medical implants are designed to replace a damaged organ or structure within the body to maintain normal function, for example as hip joint replacements. Traditionally materials such as metals, ceramics and synthetic polymers have been used to provide suitable function as implants, however these materials have been shown to cause inflammatory and immunogenic effects that are detrimental in both the short and long term. ${ }^{149}$ Biopolymers offer a potential solution to resolve these issues as they are generally biocompatible, biodegradable and non-immunogenic. Fig. 10 illustrates how nanocellulose has shown promising results for the engineering of nonbiodegradable organ implants with suitable mechanical properties and patient-specific shapes. ${ }^{150}$

\subsection{Wound healing}

Wound dressings act as barriers and protect wound areas from further harm, mainly the risk of infection from microorganisms. These dressings should be permeable to oxygen and moisture which are essential for the healing process. Biopolymers including nanocellulose have exhibited useful properties that protect the skin outside the wound, maintain suitable moisture at the wound, prevent and control microbial biofilm formation,

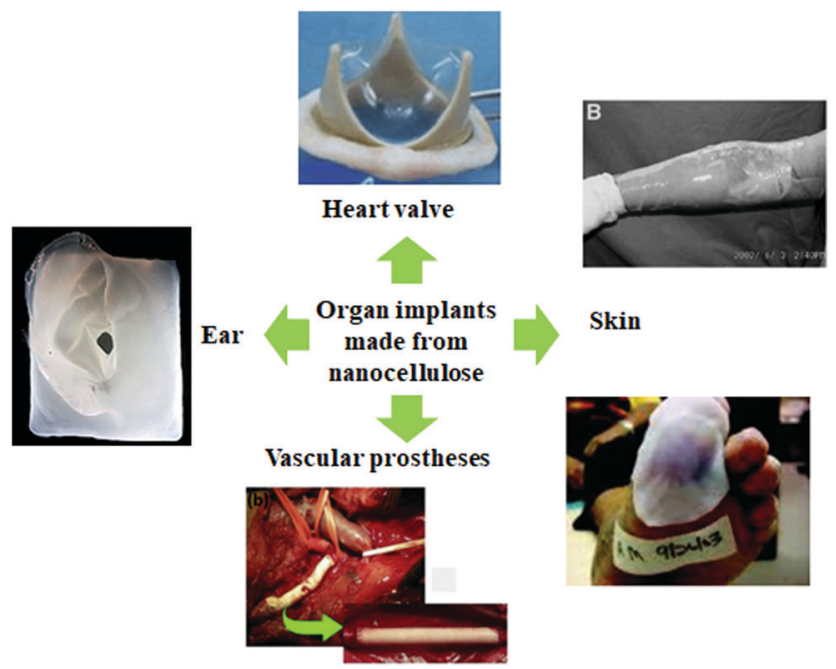

Fig. 10 The 3D printing of an ear implant made from nanocellulose. This figure was redrawn and adapted from ref. 33 and 151-154. cleanse the injured tissues, eliminate or minimise pain, remove dead spaces from non-viable tissues and control odors. ${ }^{155}$ In recent years, nanocellulose has been investigated to be used as a potential material for wound dressings. ${ }^{156}$ This is due to its high surface to volume ratio that can enhance the proliferation, migration and attachment of cells. ${ }^{157}$ The presence of abundant $-\mathrm{OH}$ groups on the surface of the nanocellulose offers a hydrated layer over the wounds. ${ }^{148}$ Besides that, nanocellulose also allows for the transfer and control as well as release of antimicrobial compounds into the wound area. This will help the healing process of those injured to become completed in a period of 10-16 days. ${ }^{158,159}$ Examples of antimicrobial compounds that have been functionalized with nanocellulose include silver nanoparticles, lysozymes, $n$-halamine, and amino acids. ${ }^{160,161}$ This developed technology can be applied for use on military casualties for a faster recovery process.

\subsection{Challenges of nanocellulose application in medicine}

One of the challenges ahead of using nanocellulose in medical applications is to understand the behavior of nanocellulose inside the body in terms of long-term toxicity, potential immunogenicity, biodistribution, circulation efficiency, biocompatibility and biodegradation. The drug delivery systems by using nanocellulose have several challenges. The problems in controlling size, shape, distribution uniformity and density of nanocellulose need to be overcome. ${ }^{162}$ Nevertheless, maintaining the morphology and dispersion of nanocellulose remain additional challenges. This requires further improvements to enhance the efficiency of nanocellulose-based drug delivery systems. As mentioned before, modification of nanocellulose can be carried out in order to prepare hyperbranched polymers through several techniques as discussed in Section 2. This new approach is also beneficial for loading of several drugs efficiently. However, an important precaution on the toxicity effect and biocompatibility of modified nanocellulose needs to be considered. Therefore, future research is urgently needed to solve these issues.

\section{Applications of nanocellulose in military acoustic materials}

Acoustical materials are a variety of foams, fabrics, and metals which are used to quiet workplaces, homes, automobiles and vehicles. These materials are developed to increase the comfort and safety of their inhabitants by reducing noise generated both inside and outside of those spaces. Apart from commercial applications, development of acoustic materials can also be beneficial for military industries. This is because several noisy pieces of equipment and processes are found throughout military operations. Fighter jets, helicopters, air missiles and infantry combat vehicles are common examples of military assets that are usually found to produce noise.

Thereby exposing service personnel to risks of hearing damage arising from hazardous noise levels in the work place. ${ }^{163}$ In fact, the military typically is exposed to some of 
the most intense sounds that can be found in any occupation. For example, military kinetic weapon systems typically cause more than $140 \mathrm{~dB}$ peak sound pressure levels (dBP), a level generally considered the maximum for a single safe unprotected exposure for impulse noise. ${ }^{163}$ Many weapon systems however cause repeated peak sound pressure impulses that over time cause degradation of hearing, if no hearing protection is used. The development of suitable effective sound attenuating materials remains an urgent needed for the military.

Nanocellulose has been found to be an ideal acoustic material. There have been investigations related to the use of nanocellulose-based composites for wideband sound absorption materials. Lavoine et al. $(2017)^{164}$ reported in their review on the acoustic properties of CNF foams obtained by homogeneous freezing. They found that at low frequencies $(<1000 \mathrm{~Hz})$, the sound absorption ability was poor, whereas at $4000 \mathrm{~Hz}$, mechanically-treated CNF and CNF functionalized with 2,2,6, 6-tetramethylpiperidin-1-yl oxyl (TEMPO) foams reached absorption ratios of 57 and 54\%, respectively. The measured sound-absorption ratios of these $3 \mathrm{D}$ foams were larger than wood-based acoustic panels using particleboard and plywood. Farid et al. (2018) ${ }^{165}$ measured the level of sound adsorption using CNC-unsaturated polyester resin composites. Based on their sound absorption test results it showed an average value of sound absorption coefficient of 0.36 to 0.46 for frequencies between 500 and $4000 \mathrm{~Hz}$ indicating that this CNC-based polyester composite material had a tendency towards wideband sound absorption and could potentially be used as an interior acoustic panel material for military vehicles.

\subsection{Challenges of nanocellulose applications as acoustic materials}

The application of nanocellulose in acoustic materials is still rarely being explored. Currently, high moisture adsorption of nanocellulose is expected to reduce the performance of the acoustic materials. Moreover, several military appliances including acoustic materials must have good water resistance. Therefore, the development of superhydrophobic nanocellulose can be done to solve this issue. Besides that, several other modifications can also be explored to improve the current performance of nanocellulose in acoustic applications, especially for the military.

\section{Present day challenges with nanocellulose production}

At present the production of nanocellulose is associated with high cost and high energy consumption. ${ }^{166}$ Despite many different sources of nanocellulose being discovered, the cost of industrial production continues to be a challenge that also needs attention. Nonetheless, progress in this matter has been accomplished in many reports which were focused on nanocellulose production scale-up and this would ultimately reduce the cost of production of nanocellulose thus making many of these advances concerning nanocellulose more viable in the future. Scientists have been exploring ways to improve the production of nanocellulose. For example, superheated steam pretreatment on cellulose has been proven to improve the nanofibrillation process by reducing the processing time of nanofibrillation by wet disk milling. ${ }^{20,167,168}$ It also could eliminate the use of chemicals in nanocellulose production. Therefore, superheated steam pretreatment is believed to reduce the production cost and processing time of nanocellulose. Besides that, scientists have discovered the progress achieved in introducing a new nanocellulose material containing lignin. The preparation of lignin-nanocellulose is a more eco-friendly approach where the use of chemicals during the delignification treatment can be reduced. ${ }^{169}$

In nanocellulose composite production, Norrahim et al. $(2018)^{8}$ and Yasim-Anuar et al. $(2019)^{46}$ discovered the ability to produce a nanocellulose composite by a one-pot process by extrusion. The one-pot process combines nanofibrillation of cellulose and compounding processes in one system. The advantage of this kind of processing lies in its efficient production of nanocellulose composites due to fewer processing steps being involved. The proposed method is possible to be commercialized due to its fast, simple and easy technique. Most of the nanocellulose reinforced composites require using a compatibilizer. Currently, scientists are continuing to investigate a green alternative in this matter. Lignin-nanocellulose was found to have better compatibility with many other polymers. This is because lignin can act as a compatibilizer between nanocellulose and polymers. Moreover, it has been reported that the presence of lignin could also increase the mechanical properties of composites. ${ }^{169,170}$

\section{Conclusions and future perspectives}

In conclusion, the usefulness of nanocellulose for various applications in the military is a promising and exciting area of current and future R\&D. Several recent developments in the application of nanocellulose related to military use were reviewed. The wide range of possibilities for surface functionalization using the chemistry of hydroxyl groups has been shown to expand the application possibilities of nanocellulose. More research can be carried out in this area to increase the effectiveness of nanocellulose as a material with military applications. Although the effectiveness of nanocellulose as a new green biobased material in the military has been demonstrated through several different studies, further improvements are still needed. R\&D ideally should involve the actual use of military technology to ensure that the properties developed truly meet military needs. For example, the effectiveness of nanocellulose as an antimicrobial material has to be tested using several known biological warfare agents. Moreover, any developed nanocellulose based filtration materials also need to be tested against real samples of chemical warfare agents such as sarin, tabun, cyanides and chlorine. Another issue of importance is related to the cost-effectiveness and availability of nanocellulose on an industrial scale. Indeed, the 
energy consumption related to the production of nanocellulose is still an issue hampering the scale-up production of nanocellulose. However, progress has been accomplished in many reports which were focused on scale-up and reduce the production of nanocellulose thus making the potential for the broader use of nanocellulose that much greater.

\section{Conflicts of interest}

There are no conflicts of interest to declare.

\section{Acknowledgements}

The authors would like to highly acknowledge financial support (UPNM/2018/CHEMDEF/ST/4) from the Ministry of Education Malaysia. The authors also gratefully acknowledge Universiti Pertahanan Nasional Malaysia (National Defence University of Malaysia).

\section{References}

1 Stockholm International Peace Research Institute, Global military expenditure sees largest annual increase in a decade-says SIPRI-reaching \$1917 billion in 2019|SIPRI, https://www.sipri.org/media/press-release/2020/global-militaryexpenditure-sees-largest-annual-increase-decade-says-siprireaching-1917-billion, (accessed 22 October 2020).

2 Congressional Research Service, Government Expenditures on Defense Research and Development by the United States and Other OECD Countries: Fact Sheet, 2020.

3 N. R. Councils, Materials Research to Meet 21st Century Defense Needs, National Academies Press, 2003.

4 S. Kalia, A. Dufresne, B. M. Cherian, B. S. Kaith, L. Avérous, J. Njuguna and E. Nassiopoulos, Int. J. Polym. Sci., 2011, 2011, 1-35.

5 P. Phanthong, P. Reubroycharoen, X. Hao, G. Xu, A. Abudula and G. Guan, Carbon Resour. Convers., 2018, 1, 32-43.

6 S. Dutta, J. Kim, Y. Ide, J. Ho Kim, M. S. A. Hossain, Y. Bando, Y. Yamauchi and K. C. W. Wu, Mater. Horiz., 2017, 4, 522-545.

7 R. Ahmad Ilyas, S. Mohd Sapuan, R. Ibrahim, H. Abral, M. R. Ishak, E. S. Zainudin, M. Asrofi, M. Siti Nur Atikah, M. R. Muhammad Huzaifah, M. A. Radzi, A. M. Noor Azammi, M. A. Shaharuzaman, N. Mohd Nurazzi, E. Syafri, H. S. Nasmi, M. N. F. Norrrahim and R. Jumaidin, J. Mater. Res. Technol., 2019, 8, 2753-2766.

8 M. N. F. Norrrahim, H. Ariffin, T. A. T. Yasim-Anuar, M. A. Hassan, H. Nishida and T. Tsukegi, IOP Conf. Ser.: Mater. Sci. Eng., 2018, 368, 1-9.

9 T. A. T. Yasim-Anuar, H. Ariffin, M. N. F. Norrrahim, M. A. Hassan, Y. Andou, T. Tsukegi and H. Nishida, Polymers, 2020, 12, 1-17.

10 H. M. Duong and S. T. Nguyen, Nano and Biotech Based Materials for Energy Building Efficiency, 2016, pp. 411-427.
11 D. Lasrado and S. Ahankari, J. Appl. Polym. Sci., 2020, 137, 1-14.

12 K. Ludwicka, M. Jedrzejczak-Krzepkowska, K. Kubiak, M. Kolodziejczyk, T. Pankiewicz and S. Bielecki, Bacterial Nanocellulose: From Biotechnology to Bio-Economy, Elsevier B.V., 2016, pp. 145-165.

13 N. Mahfoudhi and S. Boufi, Cellulose, 2017, 24, 1171-1197.

14 H. Golmohammadi, E. Morales-Narváez, T. Naghdi and A. Merkoçi, Chem. Mater., 2017, 29, 5426-5446.

15 I. M. Fareez, A. H. Jasni and M. N. F. Norrrahim, Phenolic Polymers Based Composite Materials, Springer Singapore, 2020, pp. 139-151.

16 D. Hoenders, J. Guo, A. S. Goldmann, C. Barner-Kowollik and A. Walther, Mater. Horiz., 2018, 5, 560-568.

17 W. Chen, H. Yu, Y. Liu, Y. Hai, M. Zhang and P. Chen, Cellulose, 2011, 18, 433-442.

18 C. Tian, J. Yi, Y. Wu, Q. Wu, Y. Qing and L. Wang, Carbohydr. Polym., 2016, 136, 485-492.

19 R. A. Ilyas, S. M. Sapuan, R. Ibrahim, M. S. N. Atikah, A. Atiqah, M. N. M. Ansari and M. N. F. Norrrahim, Nanocrystalline Materials, 2020, pp. 1-30.

20 M. N. F. Norrahim, H. Ariffin, M. A. Hassan, N. A. Ibrahim, W. M. Z. W. Yunus and H. Nishida, Int. J. Nanotechnol., 2019, 16, 668-679.

21 S. Iwamoto, K. Abe and H. Yano, Biomacromolecules, 2008, 9, 1022-1026.

22 M. T. Islam, M. M. Alam and M. Zoccola, Int. J. Innov. Res. Sci., 2013, 2, 5444-5451.

23 H. Voisin, L. Bergström, P. Liu and A. Mathew, Nanomaterials, 2017, 7, 1-19.

24 H. Nishida, K. Yamashiro and T. Tsukegi, in Handbook of Composite from Renewable Materials, ed. V. K. Thakur, M. K. Thakur and M. R. Kessler, Scrivener Publishing LLC, 2017, pp. 339-361.

25 L. Mo, H. Pang, Y. Tan, S. Zhang and J. Li, Chem. Eng. J., 2019, 378, 1-14.

26 A. Kardam, D. S. Rajawat, S. Kanwar and Madhubala, Recent Trends in Materials and Devices, 2017, vol. 178, pp. 57-63.

27 N. Lin and A. Dufresne, Nanoscale, 2012, 4, 3274-3294.

28 R. Rusli and S. J. Eichhorn, Appl. Phys. Lett., 2008, 93, 1-3.

29 D. Klemm, F. Kramer, S. Moritz, T. Lindström, M. Ankerfors, D. Gray and A. Dorris, Angew. Chem., Int. Ed., 2011, 50, 5438-5466.

30 V. E. Etuk, I. O. Oboh, B. R. Etuk, E. O. Johnson and K. Egemba, The European Conference on Sustainability, Energy \& the Environment 2018 Official Conference Proceedings, 2018, pp. 1-26.

31 X. Xu, F. Liu, L. Jiang, J. Y. Zhu, D. Haagenson and D. P. Wiesenborn, ACS Appl. Mater. Interfaces, 2013, 5, 2999-3009.

32 T. A. T. Yasim-anuar, H. Ariffin, M. N. F. Norrrahim and M. A. Hassan, BioResources, 2017, 12, 715-734.

33 L. G. Greca, J. Lehtonen, B. L. Tardy, J. Guo and O. J. Rojas, Mater. Horiz., 2018, 5, 408-415.

34 H. P. S. A. Khalil, Y. Davoudpour, N. Islam, A. Mustapha, K. Sudesh, R. Dungani and M. Jawaid, Carbohydr. Polym., 2014, 99, 649-665. 
35 D. Klemm, D. Schumann, F. Kramer, N. Hebler, D. Koth and B. Sultanova, Macromol. Symp., 2009, 280, 60-71.

36 D. Klemm, K. Petzold-Welcke, F. Kramer, T. Richter, V. Raddatz, W. Fried, S. Nietzsche, T. Bellmann and D. Fischer, Carbohydr. Polym., 2020, 254, 117313.

37 D. K. Patel, S. D. Dutta and K. T. Lim, RSC Adv., 2019, 9, 19143-19162.

38 Y. Chu, Y. Sun, W. Wu and H. Xiao, Carbohydr. Polym., 2020, 250, 116892.

39 LENS.ORG, Lens Scholarly Search: functionalization of nanocellulose, https://www.lens.org/lens/search/scholar/ analysis? $q=$ functionalizationofnanocellulose\&preview=true, (accessed 14 November 2020).

40 J. Higgs, How To Meet Military Packaging Standards \& Specifications, https://www.caltexplastics.com/meeting-militarypackaging-standards.html, (accessed 22 October 2020).

41 M. N. F. Norrrahim, S. M. Sapuan, T. A. T. Yasim-Anuar, F. N. M. Padzil, N. S. Sharip, L. Y. F. Ng, L. N. Megashah, S. S. Shazleen, N. F. A. Rahim, R. Syafiq and R. A. Ilyas, Food Packaging, 2020, pp. 141-170.

42 H. P. S. Abdul Khalil, Y. Davoudpour, C. K. Saurabh, M. S. Hossain, A. S. Adnan, R. Dungani, M. T. Paridah, Z. I. S. Mohamed, M. R. N. Fazita, M. I. Syakir and M. K. M. Haafiz, Renewable Sustainable Energy Rev., 2016, 64, 823-836.

43 M. A. Hubbe, A. Ferrer, P. Tyagi, Y. Yin, C. Salas, L. Pal and O. J. Rojas, BioResources, 2017, 12, 2143-2233.

44 J. T. Korhonen, M. Kettunen, R. H. A. Ras and O. Ikkala, ACS Appl. Mater. Interfaces, 2011, 3, 1813-1816.

45 P. Phanthong, P. Reubroycharoen, S. Kongparakul, C. Samart, Z. Wang, X. Hao, A. Abudula and G. Guan, Carbohydr. Polym., 2018, 190, 184-189.

46 T. A. T. Yasim-Anuar, H. Ariffin, M. N. F. Norrrahim, M. A. Hassan and T. Tsukegi, J. Cleaner Prod., 2019, 207, 590-599.

47 C. K. Saurabh, A. Mustapha, M. M. Masri, A. F. Owolabi, M. I. Syakir, R. Dungani, M. T. Paridah, M. Jawaid and H. P. S. Abdul Khalil, J. Nanomater., 2016, 2016, 1-8.

48 M. Herrera Rodriguez, Preparation and characterization of nanocellulose films and coatings from industrial bio-residues, Doctoral thesis, Luleå Tekniska Universitet, 2015.

49 N. Lani, N. Ngadi, A. Johari and M. Jusoh, J. Nanomater., 2014, 2014, 1-9.

50 G. Siqueira, J. Bras, N. Follain, S. Belbekhouche, S. Marais and A. Dufresne, Carbohydr. Polym., 2013, 91, 711-717.

51 Y. Habibi, A.-L. Goffin, N. Schiltz, E. Duquesne, P. Dubois and A. Dufresne, J. Mater. Chem., 2008, 18, 5002-5010.

52 M. E. Malainine, M. Mahrouz and A. Dufresne, Compos. Sci. Technol., 2005, 65, 1520-1526.

53 E. Kosior, R. Bragança and P. Fowler, Lightweight compostable packaging: literature review, 2006, vol. 26.

54 M. N. F. Norrrahim, H. Ariffin, M. A. Hassan, N. A. Ibrahim and H. Nishida, RSC Adv., 2013, 3, 24378-24388.

55 R. Ilyas, S. Sapuan, M. N. F. Norrrahim, T. A. T. Yasim-Anuar, A. Kadier, M. S. Kalil, M. Atikah, R. Ibrahim, M. Asrofi, H. Abral, A. Nazrin, R. Syafiq, H. Aisyah and M. Asyraf,
Advanced Processing, Properties, and Applications of Starch and Other Bio-Based Polymers, Elsevier, 2020, pp. 65-88.

56 B. Montero, M. Rico, S. Rodríguez-Llamazares, L. Barral and R. Bouza, Carbohydr. Polym., 2017, 157, 1094-1104.

57 D. M. Panaitescu, E. R. Ionita, C. A. Nicolae, A. R. Gabor, M. D. Ionita, R. Trusca, B. E. Lixandru, I. Codita and G. Dinescu, Polymers, 2018, 10, 1-24.

58 A. Ferrer, L. Pal and M. Hubbe, Ind. Crops Prod., 2017, 95, 574-582.

59 S. S. Nair, J. Y. Zhu, Y. Deng and A. J. Ragauskas, Sustainable Chem. Processes, 2014, 2, 23.

60 G. Fotie, S. Limbo and L. Piergiovanni, Nanomaterials, 2020, 10, 1726.

61 E. Lam, K. B. Male, J. H. Chong, A. C. Leung and J. H. T. Luong, Trends Biotechnol., 2012, 20, 283-290.

62 S. Chu and A. Majumdar, Nature, 2012, 488, 294-303.

63 W. Chen, H. Yu and Z. Fan, Chem. Soc. Rev., 2018, 47, 2837-2872.

64 X. Du, Z. Zhang, W. Liu and Y. Deng, Nano Energy, 2017, 35, 299-320.

65 C. Chen and L. Hu, Acc. Chem. Res., 2018, 51, 3154-3165.

66 R. Guo, L. Zhang, Y. Lu, X. Zhang and D. Yang, J. Energy Chem., 2020, 51, 342-361.

67 E. Erbas, A. Kiziltas, K. Rhodes, N. W. Emanetoglu, M. Blumentritt and D. J. Gardner, Carbohydr. Polym., 2016, 136, 1144-1151.

68 Y. Li, H. Zhu, F. Shen, J. Wan, S. Lacey, Z. Fang, H. Dai and L. Hu, Nano Energy, 2015, 13, 346-354.

69 J. Yan, Q. Wang, T. Wei and Z. Fan, Adv. Energy Mater., 2014, 4, 1-43.

70 Y. Wang, Y. Song and Y. Xia, Chem. Soc. Rev., 2016, 45, 5925-5950.

71 G. Zu, J. Shen, L. Zou, F. Wang and X. Wang, Carbon, 2016, 99, 203-211.

72 M. Yu, R. Li, M. Wu and G. Shi, Energy Storage Mater., 2015, 1, 51-73.

73 J. R. Nair, F. Bella, N. Angulakshmi, A. Manuel and C. Gerbaldi, Energy Storage Mater., 2016, 3, 69-76.

74 A. Manthiram, Y. Fu, S. Chung, C. Zu and Y. Su, Chem. Rev., 2014, 114, 11751-11787.

75 J. Kim, D. Lee, Y. Lee, W. Chen and S. Lee, Adv. Mater., 2019, 31, 1-16.

76 Z. Fang, G. Hou, C. Chen and L. Hu, Curr. Opin. Solid State Mater. Sci., 2019, 23, 100764.

77 X. Wang, L. He and C. Ju, International Conference on Manufacturing Science and Engineering, 2015, pp. 98-102.

78 P. Tayeb and A. H. Tayeb, Carbohydr. Polym., 2019, 224, 115149.

79 Y. Zhou, C. Fuentes-hernandez, T. M. Khan, J. Liu, J. Hsu and J. W. Shim, Sci. Rep., 2013, 3, 1-5.

80 M. Nogi, M. Karakawa, N. Komoda, H. Yagyu and T. T. Nge, Sci. Rep., 2015, 5, 1-7.

81 S. V. Costa, P. Pingel, S. Janietz and A. Fl, J. Appl. Polym. Sci., 2016, 133, 1-6.

82 K. Yuwawech, J. Wootthikanokkhan and S. Tanpichai, Polym. Test., 2015, 48, 12-22. 
83 Y. Zhou, T. M. Khan, J. Liu, C. Fuentes-hernandez, J. Won, E. Najafabadi, J. P. Youngblood, R. J. Moon and B. Kippelen, Org. Electron., 2014, 15, 661-666.

84 K. Miettunen, J. Vapaavuori, A. Tiihonen, A. Poskela, P. Lahtinen, J. Halme and P. Lund, Nano Energy, 2014, 8, 95-102.

85 C. Chen and L. Hu, Acc. Chem. Res., 2018, 51, 3154-3165.

86 F. Luo, K. Wu, D. Li, J. Zheng, H. Guo, Q. Zhao and M. Lu, Polym. Compos., 2015, 38, 2762-2770.

87 M. E. Mngomezulu and M. J. John, Handbook of Nanocellulose and Cellulose Nanocomposites, 2017, pp. 235-272.

88 T. Kashiwagi, F. Du, J. F. Douglas, K. I. Winey, R. H. Harris and J. R. Shields, Nat. Mater., 2005, 4, 928-933.

89 B. Wicklein, A. Kocjan, G. Salazar-Alvarez, F. Carosio, G. Camino, M. Antonietti and L. Bergström, Nat. Nanotechnol., 2015, 10, 277-283.

90 B. Wicklein, D. Kocjan, F. Carosio, G. Camino and L. Bergström, Chem. Mater., 2016, 28, 1985-1989.

91 D. Wang, H. Peng, Y. Wu, L. Zhang, M. Li, M. Liu, Y. Zhu, A. Tian and S. Fu, ACS Sustainable Chem. Eng., 2020, 8, 4331-4336.

92 J. Pichtel, Appl. Environ. Soil Sci., 2012, 2012, 1-33.

93 T. D. Fife, M. J. A. Robb, K. K. Steenerson and K. C. Saha, Front. Neurol., 2018, 9, 3-8.

94 P. Sangwan, K. Sharma, M. Celin and B. Kiran, Microbial Resource Conservation, Springer, 2018, pp. 431-451.

95 A. Chaalane, R. Chemam, M. Houabes, R. Yahiaoui, A. Metatla, B. Ouari, N. Metatla, D. Mahi, A. Dkhissi and D. Esteve, J. Phys.: Conf. Ser., 2015, 660, 1-6.

96 O. P. Andrew and O. G. Echiye, J. Eng. Appl. Sci. Res., 2016, 8, 75-85.

97 G. Xia, H. Li, Y. Ding, L. Wei, S. Chen and D. Yu, Acta Astronaut., 2020, 171, 290-299.

98 Y. Yang, F. Zhao, X. Huang, J. Zhang, X. Chen, Z. Yuan, Y. Wang, H. Li and S. Li, Chem. Eng. J., 2020, 402, 126275.

99 W. Ao, Z. Fan, L. Liu, Y. An, J. Ren, M. Zhao, P. Liu and L. K. B. Li, Combust. Flame, 2020, 220, 288-297.

100 C. Vijay and P. A. Ramakrishna, Combust. Flame, 2020, 217, 321-330.

101 L.-C. Zhang-Yunhua, Z.-Z. Lv-Yanyan, S.-Z. Wang-Feijun and W.-X. Zuo-Yingying, Integr. Ferroelectr., 2016, 171, 115-123.

102 S. Yan, G. Jian and M. R. Zachariah, ACS Appl. Mater. Interfaces, 2012, 4, 6432-6435.

103 S. H. Jamal, N. J. Roslan, N. A. A. Shah, S. A. M. Noor, K. K. Ong and W. M. Z. W. Yunus, Mater. Today: Proc., 2020, 29, 185-189.

104 A. Mautner, Polym. Int., 2020, 69, 741-751.

105 N. M. Saleh, N. N. A. N. Wee, N. I. M. Juber and M. N. F. Norrrahim, Sains Malays., 2020, 49, 2477-2486.

106 M. N. F. Norrrahim, M. A. Idayu Abdul Razak, N. A. Ahmad Shah, H. Kasim, W. Y. Wan Yusoff, N. A. Halim, S. A. Mohd Nor, S. H. Jamal, K. K. Ong, W. M. Zin Wan Yunus, V. F. Knight and N. A. Mohd Kasim, RSC Adv., 2020, 10, 4465-4489.

107 M. A. I. A. Razak, M. N. F. Norrrahim, O. K. Khim, S. A. M. Noor, N. A. Halim, N. A. A. Shah, V. F. Knight,
W. M. Z. W. Yunus and N. A. M. Kasim, Malaysian J. Anal. Sci., 2020, 24, 772-782.

108 S. Bolisetty, M. Peydayesh and R. Mezzenga, Chem. Soc. Rev., 2019, 48, 463-487.

109 J. Saleem, U. Bin Shahid, M. Hijab, H. Mackey and G. Mckay, Biomass Convers. Biorefin., 2019, 9, 775-802.

110 S. Rasalingam, R. Peng and R. T. Koodali, J. Nanomater., 2014, 2014, 1-42.

111 F. Fu and Q. Wang, J. Environ. Manage., 2011, 92, 407-418.

112 T. Suopajärvi, E. Koivuranta, H. Liimatainen and J. Niinimäki, J. Environ. Chem. Eng., 2014, 2, 2005-2012.

113 K. P. Y. Shak, Y. L. Pang and S. K. Mah, Beilstein J. Nanotechnol., 2018, 9, 2479-2498.

114 P. G. Moradeeya, M. A. Kumar, R. B. Thorat, M. Rathod, Y. Khambhaty and S. Basha, Cellulose, 2017, 24, 1319-1332.

115 F. Chai, R. Wang, L. Yan, G. Li, Y. Cai and C. Xi, Carbohydr. Polym., 2020, 245, 1-9.

116 T. Shahnaz, V. Sharma, S. Subbiah and S. Narayanasamy, J. Water Process Eng., 2020, 36, 1-12.

117 F. Frischknecht, Eur. Mol. Biol. Organ., 2003, 4, 47-52.

118 Suman, A. Kardam, M. Gera and V. K. Jain, Environ. Technol., 2014, 36, 706-714.

119 B. K. Nath, C. Chaliha, E. Kalita and M. C. Kalita, Carbohydr. Polym., 2016, 148, 397-405.

120 O. Gustafsson, S. Gustafsson, L. Manukyan and A. Mihranyan, Membranes, 2018, 8, 1-12.

121 G. Metreveli, L. Wågberg, E. Emmoth, S. Belák, M. Strømme and A. Mihranyan, Adv. Healthcare Mater., 2014, 3, 1546-1550.

122 M. Asper, T. Hanrieder, A. Quellmalz and A. Mihranyan, Biologicals, 2015, 43, 452-456.

123 G. M. N. Islam, A. Ali and S. Collie, Cellulose, 2020, 27, 6103-6131.

124 F. Steffens, S. E. Gralha, I. L. S. Ferreira and F. R. Oliveira, Key Eng. Mater., 2019, 812, 120-126.

125 C. Ngô and M. Van de Voorde, Nanotechnology in a Nutshell, 2014, pp. 321-329.

126 K. Galster and M. L. Nosch, Text. Hist., 2010, 41, 1-5.

127 J. R. Owens, Functional Textiles for Improved Performance, Protection and Health, Woodhead Publishing Limited, 2011, pp. 249-268.

128 A. Schmidt, R. Paul, E. Classen, S. Morlock and J. Beringer, Performance Testing of Textiles: Methods, Technology and Applications, Elsevier Ltd, 2016, pp. 25-37.

129 R. G. Revaiah, T. M. Kotresh and B. Kandasubramanian, J. Text. Inst., 2020, 111, 273-308.

130 K. Srinivas, J. Chem. Pharm. Res., 2016, 8, 173-180.

131 A. K. Yetisen, H. Qu, A. Manbachi, H. Butt, M. R. Dokmeci, J. P. Hinestroza, M. Skorobogatiy, A. Khademhosseini and S. H. Yun, ACS Nano, 2016, 10, 3042-3068.

132 R. Ilyas, S. Sapuan, M. Atikah, M. Asyraf, S. A. Rafiqah, H. Aisyah, N. M. Nurazzi and M. Norrrahim, Text. Res. J., 2020, 1-16.

133 R. Mishra, J. Militky, V. Baheti, J. Huang, B. Kale, M. Venkataraman, V. Bele, V. Arumugam, G. Zhu and Y. Wang, Text. Prog., 2014, 46, 133-226. 
134 P. Panchal, E. Ogunsona and T. Mekonnen, Processes, 2019, 7, 10.

135 G. P. Krueger, Advances in military textiles and personal equipment, Woodhead Publishing Limited, 2012, pp. 64-82.

136 C. Maury, F. Crispino and É. Loranger, BioResources, 2019, 14, 4157-4170.

137 J. Steele, H. Dong, J. F. Snyder, J. A. Orlicki, R. S. Reiner and A. W. Rudie, International SAMPE Technical Conference, 2012, pp. 1-8.

138 N. Toha, W. M. H. W. Yaa'cob, N. A. M. Razali, R. A. A. Rusdi, A. Ismail, K. Z. K. Ahmad and F. Abdul, Int. J. Curr. Res. Sci. Eng. Technol., 2018, 1, 566.

139 D. W. Wei, H. Wei, A. C. Gauthier, J. Song, Y. Jin and H. Xiao, J. Bioresour. Bioprod., 2020, 5, 1-15.

140 R. Nayak, L. Wang and R. Padhye, Electronic Textiles: Smart Fabrics and Wearable Technology, Elsevier Ltd, 2015, pp. 239-256.

141 A. Hebeish, S. Farag, S. Sharaf and T. I. Shaheen, Carbohydr. Polym., 2016, 151, 96-102.

142 O. Nechyporchuk, J. Yu, V. A. Nierstrasz and R. Bordes, ACS Sustainable Chem. Eng., 2017, 5, 4793-4801.

143 O. A. T. Dias, S. Konar, A. L. Leão, W. Yang, J. Tjong and M. Sain, Front. Chem., 2020, 8, 1-15.

144 N. Sharip, T. Yasim-Anuar, M. Norrrahim, S. Shazleen, N. M. Nurazzi, S. Sapuan and R. Ilyas, Composites in Biomedical Applications, CRC Press, 2020, pp. 161-190.

145 N. S. Sharip and H. Ariffin, Nanostructured Polymer Composites for Biomedical Applications, Elsevier, 2019, pp. 385-404.

146 J. Rojas, M. Bedoya and Y. Ciro, Cellulose - Fundamental Aspects and Current Trends, IntechOpen, 2015.

147 C. C. Ude, A. Miskon, R. B. H. Idrus and M. Bin Abu Bakar, Mil. Med. Res., 2018, 5, 1-18.

148 J. Moohan, S. A. Stewart, E. Espinosa, A. Rosal, A. Rodríguez, E. Larrañeta, R. F. Donnelly and J. Domínguez-Robles, Appl. Sci., 2020, 10, 1-25.

149 R. Rebelo, M. Fernandes and R. Fangueiro, Procedia Eng., 2017, 200, 236-243.

150 J. Sundberg, P. Gatenholm, R. Mu and K. S. Stok, J. Mech. Behav. Biomed. Mater., 2013, 22, 12-21.

151 N. Lin and A. Dufresne, Eur. Polym. J., 2014, 59, 302-325. 152 A. Gumrah Dumanli, Curr. Med. Chem., 2016, 24, 512-528.

153 B. M. Cherian, A. L. Leão, S. F. de Souza, G. M. de Olyveira, L. M. M. Costa, C. V. S. Brandão and S. S. Narine, Adv. Struct. Mater., 2013, 18, 337-359.
154 H. P. Abdul Khalil, A. H. Bhat, A. Abu Bakar, P. M. Tahir, I. S. Zaidul and M. Jawaid, Handbook of Polymer Nanocomposites. Processing, Performance and Application: Volume C: Polymer Nanocomposites of Cellulose Nanoparticles, Springer Berlin Heidelberg, 2015, pp. 475-511.

155 G. D. Mogos and A. Mihai, Int. J. Pharm., 2014, 463, 127-136.

156 L. Bacakova, J. Pajorova, M. Bacakova, A. Skogberg, P. Kallio, K. Kolarova and V. Svorcik, Nanomaterials, 2019, 9, 1-39.

157 F. C. Claro, C. Jordão, B. M. de Viveiros, L. J. E. Isaka, J. A. Villanova Junior and W. L. E. Magalhães, Cellulose, 2020, 27, 10765-10779.

158 T. Hakkarainen, R. Koivuniemi, M. Kosonen, C. Escobedolucea, A. Sanz-garcia and J. Vuola, J. Controlled Release, 2016, 244, 292-301.

159 G. Chinga-carrasco and K. Syverud, J. Biomater. Appl., 2014, 29, 423-432.

160 K. Roemhild, C. Wiegand, U. Hipler and T. Heinze, Macromol. Rapid Commun., 2013, 34, 1767-1771.

161 K. A. I. Hua, Nanocellulose for Biomedical Applications: Modification, Characterisation and Biocompatibility Studies, Doctoral thesis, Acta Universitatis Upsaliensis, 2015.

162 D. Trache, A. F. Tarchoun, M. Derradji, T. S. Hamidon, N. Masruchin, N. Brosse and M. H. Hussin, Front. Chem., 2020, 8, 1-33.

163 C. Jokel, K. Yankaskas and M. B. Robinette, J. Acoust. Soc. Am., 2019, 146, 3832-3838.

164 N. Lavoine and L. Bergstrom, J. Mater. Chem. A, 2017, 5, 16105-16117.

165 M. Farid, A. Purniawan, D. Susanti, S. Priyono, H. Ardhyananta and M. E. Rahmasita, AIP Conf. Proc., 2018, 1945, 1-6.

166 N. Mahfoudhi and S. Boufi, Cellulose-Reinforced Nanofibre Composites, Elsevier Ltd, 2017, pp. 277-304.

167 L. N. Megashah, H. Ariffin, M. R. Zakaria, M. A. Hassan, Y. Andou and F. N. M. Padzil, Cellulose, 2020, 27, 7417-7429.

168 M. N. F. Norrahim, H. Ariffin, T. A. T. Yasim-Anuar, F. Ghaemi, M. A. Hassan, N. A. Ibrahim, J. L. H. Ngee and W. M. Z. W. Yunus, Cellulose, 2018, 25, 3853-3859.

169 C. M. Ewulonu, X. Liu, M. Wu and H. Yong, J. Bioresour. Bioprod., 2019, 4, 3-10.

170 S. Sahoo, M. Misra and A. K. Mohanty, Composites, Part A, 2011, 42, 1710-1718. 